\title{
ANTECEDENTES DE BARRANQUILLA (COLOMBIA), CARACTERIZACIÓN DE SU METROPOLIZACIÓN
}

\author{
Javier Augusto Buitrago Rey \\ Maestría en Derecho Administrativo (C), Universidad Externado de Colombia. \\ Especialista en Derecho Público, Universidad Externado de Colombia. \\ Docente Investigador Universidad Santo Tomás Bucaramanga (Colombia). \\ Correo electrónico: buitragorey@hotmail.com
}

\begin{abstract}
Resumen
El eje de crecimiento económico y social de Barranquilla es la expectativa latente de trabajo que genera el Puerto y su constante ampliación y modernización como lo fue el aforo en la recesión de la década de los años veinte, con la reinauguración en los cuarenta, con la bonanza cafetera de los cincuenta y setenta, en la apertura económica de los noventa y ahora con la entrada en operatividad de los Tratados de Libre Comercio con los países que conforman la América del Norte y los próximos con Asia como son los de Corea del Sur y Japón y si las negociaciones culminan bien quizás China. En estas líneas se propone evidenciar entonces las ventajas de la actividad de la conurbación barranquillera para sugerir estrategias tendientes a la gobernanza de su área metropolitana.
\end{abstract}

Palabras Clave: Área Metropolitana, metropolización, integración, gobernanza

\begin{abstract}
The axis of Barranquilla's economic and social growth is the latent expectation of work that generates the Port and his constant extension and modernization like it it was the appraisal in the recession of the decade of the twenties, with the reinauguration in the forties, with the coffee prosperity of the fifties and seventies, in the economic opening of the nineties and now with the entry in operability of the Agreements of Free Trade with the countries that shape the North America and the near ones with Asia since are those of South Korea and Japan and if the negotiations reach probably well China. In these lines it proposes to demonstrate then the advantages of the activity of the conurbatiónbarranquillera to suggest strategies tending to the governance of his metropolitan area.
\end{abstract}

Key Words: Metropolitan area, metropolization, integration, governance.

\section{Résumé}

L'axe de croissanceéconomique et sociale de Barranquilla est l'attente latente de travail qui génère le Port et son agrandissement constant et modernisation comme c'il était la capacité dans la récession de la décennie des années vingt, avec la reinauguration dans les quarante, avec la bonace de café des cinquante et soixantedix, dans l'ouverture économique des quatre-vingt-dix et maintenant avec l'entrée dans une opérativité des Traités de Commerce Libre avec les pays qui conforment l'Amérique du Nord et les proches à l'Asie comme c'est ceux-là de la Corée du Sud et Japon et si les négociations culminent bien peut-être la Chine. Dans ces lignesil se propose de mettre en évidence alors les avantages de l'activité du conurbation barranquillera pour suggérer des stratégies tendantes à la gouvernance de son aire métropolitaine.

Mots-clés: Une aire Métropolitaine, métropolisation, une intégration, une gouvernance. 

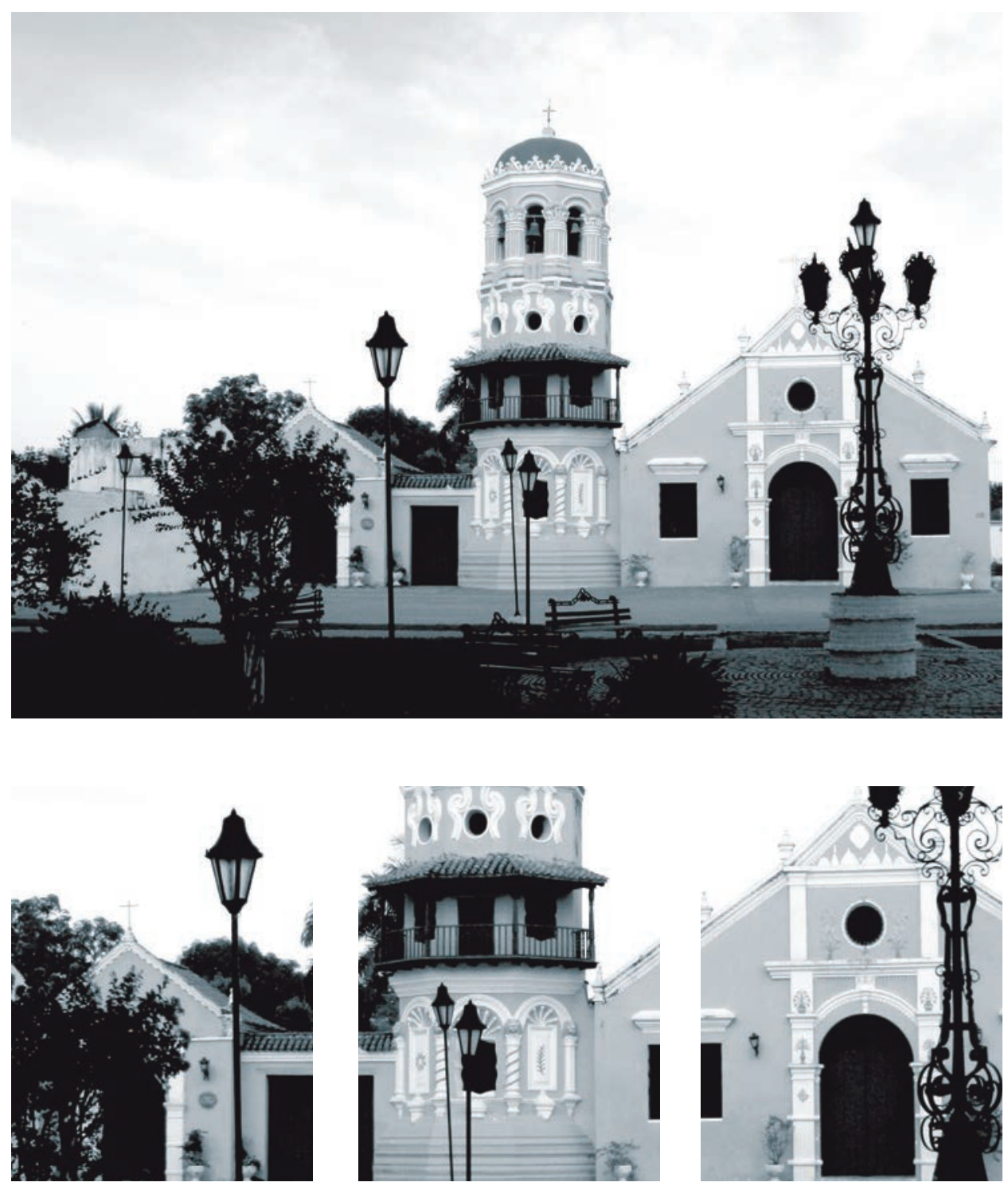

Iglesia de Santa Bárbara - Mompóx - Colombia Martín Emilio Hernández Manrique 


\section{ANTECEDENTES DE BARRANQUILLA (COLOMBIA), CARACTERIZACIÓN DE SU METROPOLIZACIÓN *}

Javier Augusto Buitrago Rey

\section{INTRODUCCIÓN}

El trabajo de investigación mencionado tiene por objeto identificar la metropolización como proceso en Colombia, es por ello que este escrito debe iniciar desde los primeros vestigios de asientos humanos en territorio barranquillero para determinar así la riqueza de su posición estratégica, de su conversión de cruce de vías a caserío de libertos, de poblado agrícola a comercial, de comercial a industrial y de industrial a portuario. Para empezar a hablar de Barranquilla, de sus orígenes, de su evolución como ciudad, de su conurbación con sus vecinos y de su ordenamiento actual, se hace necesario, entonces, abordarla desde los hitos más destacables de la transformación urbana que la especie humana ha realizado sobre el espacio geográfico donde se ubica hoy el Área Metropolitana de Barranquilla a partir de las correspondientes concepciones que sirven de fundamento para ver al hombre, y a la sociedad que la integra, en el tiempo.

Las evidencias de Carbono 14 nos indican que los primeros asentamientos se produjeron a finales del siglo IV después de Cristo. En el entorno de Barranquilla se encuentran importantes evidencias de presencia humana temprana y donde

El artículo es producto del Proyecto de Investigación: Ingobernabilidad de las Áreas Metropolitanas: un problema de etiología normativa. - Cuarta Convocatoria Interna Universidad Santo Tomás 2010, adelantada por el autor (co-investigador). Grupo Derecho Público USTABGA, Facultad de Derecho, Universidad Santo Tomás Bucaramanga-Colombia. 
se produjeron importantes cambios en el modo de vida. Tal es el caso de Puerto Hormiga, cerca de la desembocadura del Canal del Dique en Cartagena, donde se encontró una de las cerámicas más antiguas del continente. El comienzo de la agricultura y de la vida aldeana también tiene su manifestación en la región en el sitio Malambo (Villalón Donoso, 2005).

La primera Barranquilla nace como un asentamiento precolombino de índole social, pues desde sus inicios fue destacada como ese punto geográfico donde todo confluye, identificado por el historiador Jorge Villalón Donoso como: un "cruce de vías", toda vez que seguramente los primeros transeúntes se detuvieron a consumir alimentos, mientras decidían qué camino tomar, algunos se quedaron para proporcionarlos, fue allí cuando este parador se empezó a identificar entre los nómades como barranquillas.

Al aumentarse la población, la paz y equilibrio que se mantuvo hasta ese momento colapsó, por lo tanto, el asentamiento desapareció, pero su ubicación estratégica siguió en sus mentes pese a reubicarse en malambo (más hacia la sabana, costado sur oriental del departamento del Atlántico) donde llegaron a recoger los productos silvestres de la tierra, al ya no cubrir éstos la sustentabilidad de la familia, vieron en la agricultura una práctica que diera solución a estos acontecimientos, fue así como empezaron a presentarse las primeras manifestaciones sedentarias; pero, éstas no fueron producto de la improvisación ya que se escogían tierras consideradas buenas, calificadas así en gracia a aspectos diversos que para la época de decisión fueron los que les brindarían bienestar a los integrantes del grupo, entonces nace la iniciativa de cultivar los mismos productos en la extensión de tierra sobre la cual los extraían de manera silvestre. A este grupo centrado en Malambo se le pierde rastro por diversos factores, tal vez cayeron abatidos por las recias campañas colonizadoras consecuentes con la fiereza, o su fama, de la etnia caribe, lo que nos llevó a ubicar el tema entonces a la barranquilla colombina.

\section{LOS PRIMEROS REGISTROS COMO POBLADO}

Todo poblado medieval tuvo en sus orígenes varios problemas, se nombran dos de los más recurrentes: primero el de su legalización, entendido como el reconocimiento oficial como poblado, que puede ser de dos formas, por fundación, como es el caso de Santa Marta y de allí que su distribución cumplió con los patrones reales: una plaza rodeada de los edificios de la administración pública seguida por las edificaciones de las personalidades opulentas hasta acomodar a las afueras a las servidumbres y soldados; la otra, la que le correspondió a Barranquilla fue la del reconocimiento oficial posterior a su creación y que fue derivaba del patrocinio de una guerra separatista; y segundo, el de planificación espacial, ya que en esa época no se cuestionaba si su distribución fuera o no idónea o que ésta permitiera o no enfrentar las necesidades que la explosión demográfica futura impondría de comunicación, provisión de productos, de servicios de agua y de termas que favorecían la higiene 
del lugar; al parecer el ordenamiento de las urbs ${ }^{l}$ iniciales le funcionó a los primeros poblados que al convertirse en posteriores ciudades presentaron problemas en su distribución fenómeno que debió identificarse, prevenirse y superarse a su tiempo en el sentir del maestro de la revolución científica: esas viejas ciudades que no fueron al principio sino aldeas y se convirtieron con el transcurso del tiempo en grandes ciudades, están ordinariamente muy mal trazadas si las comparamos con esas plazas regulares que un ingeniero diseña a su gusto en una llanura (Descartes, 1986).

En consecuencia, el requisito más importante para ser una gran ciudad, una metrópoli, es la adecuada planificación de su zona de explosión urbana desde y hacia el centro, sin una eficiente comunicación con su centro de poder no hay desarrollo y sin éste no hay ciudad. Entonces, la historia de la humanidad ha evolucionado de acuerdo a los espacios geográficos que se han escogido como punto de encuentro o punto fundacional de los poblados antiguos; en primera instancia, el clima y la geografía cambian al hombre pero la tendencia moderna es el que hombre ahora adapta el espacio geográfico a la satisfacción de las necesidades básicas; "de allí que su hábitat sea producto de las transformaciones que, a través de su organización social, ha hecho de las condiciones naturales." (Llanos Enríquez, 2007)

En el caso de Barranquilla, uno de los primeros registros como poblado, procede de 1533, y se menciona como ese asentamiento comercial (solo comercial, ausente de viviendas), que servía de paraje necesario para preparar el abordamiento del Río Magdalena; ese $\mathrm{Sitio}^{2}$ es enunciado en las crónicas de la bitácora de Fundación de Cartagena de Indias, escrita por Gonzalo Fernández de Oviedo y Valdés, como el poblado de indios Camacho: "estos grupos utilizaron una pauta de poblamiento disperso" (Villalón Donoso, 2005). Los poblados mencionados por Fernández de Oviedo estaban ubicados en jurisdicción de la gobernación de Santa Marta: a "orilla del río, o de la ciénaga, lo que hoy son los llamados caños, era un centro de intercambios y de trueque", donde era posible comprar y vender, en el atracadero de canoas autóctonas, mercadería en general, sal y productos de mar; pues la gran mayoría de ellas estaban llenas de camarones secos y las demás flotaban con variados artículos que deberían llevarse, en contra corriente, río arriba (se hacía alusión al Magdalena) $)^{3}$.

$1 \quad$ El término urbs fue utilizado por los romanos para definir la materialidad que les fuera a servir de cerco a los linderos de la ciudad; es decir, las murallas, las puertas, las termas o las calles, entre otros. (Sánchez Bonett, 2003)

2 Sitio es la denominación dada por la corona en reconocimiento a un asentamiento. Generalmente se extendía capitulaciones para fundar poblados como Sitio, Villas y Ciudades. (Ospino Contreras, 2003)

3 Tomado de la obra escrita por Jorge Villalón Donoso y Jesús Ferro Bayona: Historia de Barraquilla. Página 97 del libro digital, disponible en http://books.google.com/books?id=N5uodHjBt6sC\&pg=PA $97 \& 1 \mathrm{pg}=\mathrm{PA} 97 \& \mathrm{dq}=$ gonzalo + fernande $\mathrm{d}+\mathrm{de}+$ oviedo $+\mathrm{y}+$ valdes + sobre + barranquilla $\&$ source $=$ web $\&$ ots=e7 KJIKbzMK\&sig=P9fV1a5H7qlThB2udbOgcuTKXRo\#v=onepage \&q\&f=false 


\subsection{El Don que cambió el pago a sus libertos por tierras}

Este punto de abastecimiento (el mencionado en el subtítulo anterior) se fortalece al aumentar la demanda de víveres, el consumo se convierte entonces en fuente de riqueza que lleva a, que en el periodo colonial, siglo XVII de nuestra era, de manera espontánea surjan las primeras edificaciones que en su conjunto formaron el primer caserío de mestizos libres; para 1629, la hacienda San Nicolás de Tolentino, terreno que concentra a los indios Camacho, sufre un necesario cambio en su distribución, al abrir espacios; por órdenes de su propietario don Nicolás de Barros y de la Guerra, bisnieto del segundo encomendero de Galapa; para que sus concertados libres levantaran, dentro de los límites de sus terrenos, las propiedades y edificaciones requeridas a cambio de mantener los cultivos y la recolección de las cosechas; estos fueron los primeros brotes evidenciados de urbanismo que se forjó en las tierras donde actualmente se encuentra el centro histórico de Barranquilla que, a su vez, desde 1681; este sitio, por sus actividades agropecuarias, de comercio y de transporte; fue asemejado como poblado, por lo tanto, ya no se referían a él como Hacienda San Nicolás sino como "las Barrancas de San Nicolás".

\subsection{Los primeros trazos de un poblado de iniciativa privada}

Hacia 1772, cinco años antes del censo realizado por Juan García Turín, Francisco Escudero, el Obispo Diego de Peredo se refiere a Barranquilla en el documento "Noticia Historial” como "Sitio de libres, en la orilla de una ciénaga o caño del río de la Magdalena; tiene iglesia parroquial de piedra, madera y teja, muy capaz y decente, administra 399 familias y 1404 almas de confesión y 30 esclavos. Como el número total de almas era de 2633 y las casas eran 389, se tiene que el término medio de personas por casas es de 6.5. Por otra parte, estimado que cada manzana tuviera unas veinticinco (25) casas, se tendría que quizás aquel pequeño "Sitio" podría contar con unas 21 manzanas, que ocuparían, sin incluir calles y plazas, más o menos igual número de hectáreas. Como quien dice, tres calles de siete (7) cuadras de largo por tres (3) de ancho, o cuatro (4) calles de cinco (5) cuadras de largo por cuatro (4) de ancho. Tales podrían ser, las dimensiones supuestas de San Nicolás de Barranquilla en aquella época.Una visión un poco más completa de lo que era el Sitio de San Nicolás de Barranquilla, nombre con el que aparece en 1777, la tenemos a partir del censo realizado ese mismo año por el Corregidor y Justicia Mayor del Partido de Tierradentro, Juan García Turín, según el cual Barranquilla tenía entonces 526 vecinos, 2586 almas, 5 naturales y 42 esclavos, para un total de 2633 almas. Ese total no incluye párrocos ni autoridades eclesiásticas. (Ospino Contreras, 2003)

Con esta información podríamos aventurarnos a delimitar lo que fue el Sitio de San Nicolás de Barranquilla, el cual estaba levantado en los terrenos de mayor altura al flujo de agua que rodeaba las barrancas o barranquillas que se demarcaron en un comienzo por el encierro natural derivado del recorrido de los arroyos y caños; 
por ello, se parte del punto sobre el cual se tiene información de su existencia en el censo de 1777': el antiguo cementerio (el primero que operó en este Sitio); se parte del cementerio porque para la época los cementerios se constituían en la frontera del poblado, pues éstos estaban ubicados siempre en las afueras del asentamiento humano; ubicado junto a este se encontraba la añeja Iglesia situada en la plazuela que posteriormente se conocería como La Cruz Vieja ${ }^{5}$; se toma la ribera del Caño del Mercado rumbo oriente, paralelo a esta ribera se erigió la calle más antigua de Barranquilla conocida en esta época como la Calle Ancha (hoy es el famoso paseo Bolívar) hasta llegar a la plaza de San Nicolás donde las casas, construidas en mampostería, que conforman las manzanas levantadas en el costado sur sirven de urbs que cierra esa frontera hasta la plaza Ujueta. La plaza Ujueta estaba anclada a orillas del antiguo Caño de Soledad (sur de lo que hoy es Barranquilla), que para ese tiempo se le conocía como Caño Arriba, y operaba como principal puerto en ese entonces; para finalizar se dirige el trazado, tomando rumbo occidente, hacia la Iglesia de San Nicolás, pues en esta época la iglesia debería ser el principio de todo poblado y por ello es que detrás de ella se dejaba siempre los terrenos en reserva, en el caso de Barranquilla esta iglesia se distanciaba en aproximadamente una cuadra del arroyo de La Paz, hoy carrera 40 (Baena \& Vergara, 1922).

Revisado el trazado marcado por los autores del libro "Barranquilla, su pasado y su presente" se puede determinar que el área resultante de esta delimitación es de 23.79 hectáreas que conforman 21 manzanas organizadas longitudinalmente: 7 manzanas de frente por 3 de fondo ${ }^{6}$.

\section{BARRANQUILLA, SUS TRANSFORMACIONES}

La visión capitalista que fuera puesta en el nuevo mundo cuando se refundó América, como resultado de las libertades ganadas con las guerras de independencia junto a los esfuerzos de sus líderes en establecer comercio entre la naciente república y la economía mundial, pues sin ella serían sólo unos pequeños poblados con infraestructura poco notable; por ello, las municipalidades colombianas sufrieron la influencia de la ciudad capitalista europea que pasó por diferentes etapas, que aunque mantenía su lógica filosófica; éstas produjeron drásticas transformaciones basadas en "recursos materiales disponibles, la organización de la producción, la regulación socio-laboral y la presencia institucional del Estado y la organización laboral" (Méndez, 1997). Para explicarlo más a fondo es relevante parafrasear a David Harvey quien establece que al explotarse exageradamente la mano de obra

$4 \quad$ Ver Plano 1.

5 La Cruz Vieja estaba ubicada hoy en Barranquilla entre la carrera 44 o la esquina del Cuartel y la calle 32 o la esquina de la Calle del Comercio; es decir, en predios donde se levantó de manera posterior el Teatro Municipal.

6 Ver Plano 2. 
para producir más ingresos, se fuerza a la población desempleada a desplazarse a las urbes capitalistas para lograr una oportunidad como obreros y acomodarse, en un comienzo, en el perímetro urbano de la municipalidad, en los barrios ilegales, para subsistir, y cobijar la esperanza de mejorar su estilo de vida al ser obreros estables se ubicaban en barrios populares construidos con iniciativa estatal para trabajadores; por ello, el autor señala que el capitalismo "construye y reconstruye una geografía a su propia imagen"; es decir, bordes de miseria en las ciudades (desarrolladas, en vía de desarrollo o subdesarrolladas; ricas, pudientes o pobres) donde se ubican quienes llegan en busca de oportunidades junto a ella se levanta los límites de la ciudad con la construcción de barrios destinados para la clase proletaria lo que expande el área urbana de la ciudad a merced del crecimiento económico de los industriales de la región; por ello, con el fin de facilitar el proceso de acumulación de capital la ciudad ha avanzado sobre tres etapas: la ciudad de la revolución Industrial, la ciudad del ciclo monopolista del capitalismo, y la ciudad de la Globalización.

\subsection{La ciudad de la Revolución Industrial}

La Revolución Industrial, produce una transformación del espacio de la ciudad, lo que significó un cambio en el uso del suelo; la municipalidad pasó de ser un centro comercial y artesanal, a ser un centro industrial. La proliferación de innumerables fábricas, incorporó la producción a territorios que anteriormente no tenían esa función; es decir, acarreó una expansión territorial; al crecer la industria nace una nueva clase social: la obrera y su aumento considerable creció la población urbana, así fue, como el principal centro de la industrialización: Londres, para finales del siglo XVIII, se convierte en la primera, de Europa, en alcanzar un millón de habitantes.

La consolidación de la ciudad como espacio "natural" del sistema capitalista, se produjo a partir de finales del siglo XVIII, como consecuencia de las revoluciones económicas que se iniciaron en esos momentos y continuaron hasta mediados del siglo XIX. La Revolución Industrial, la de los Transportes y la Agraria, entre otras, impulsaron el desarrollo de la ciudad y convirtieron este espacio en el más importante y dinámico hasta tal punto que hoy, la mayor parte de las actividades económicas y de la población mundial se ubican en los espacios urbanos. (Llanos Enríquez, 2007)

Bajo esta condición, el poblado "San Nicolás de Barranquilla", en el curso del siglo XVIII, es aún considerado una pequeña aldea a orillas del río Magdalena, queda estable, por ello, no es atractivo para los movimientos económicos del país pues la hacen a un lado de la Historia comercial de la región; de esta centuria se resalta el título de "Villa" conferido a Barranquilla (Nótese que en este documento se suprime el apelativo de San Nicolás) por el Presidente Gobernador del Estado de Cartagena, Manuel Rodríguez Torices, como reconocimiento a los integrantes de este poblado por su patriotismo en el acompañamiento en la guerra de independencia de Cartagena, esta fue una estratagema para lograr el apoyo de los barranquilleros para su nueva campaña: rescatar a Santa Marta del control del Rey de España. 
Lo que apuntala a esta Villa como puerto, es la creciente navegación del río Magdalena y más tarde el Puerto catapulta a Barranquilla como ciudad. Para 1824, se introdujo, por iniciativa del alemán Juan Bernardo Elbers, la navegación a vapor por el río Magdalena, ya para mediados del siglo XIX (1842) se reinician las actividades portuarias en Barranquilla, actividades que se mantuvieron cerradas a través del Decreto 1838 de 1821, los veinte años de cierre portuario fueron producto de la política de mantener buenas relaciones con sus vecinos: Santa Marta y Cartagena; pero en especial con Cartagena con la cual se mantenía aún la relación de amistad y, por lo tanto, los congresistas barranquilleros aceptaron la solicitud de homólogos cartageneros. Con el cierre de actividades portuarias Barranquilla es vista como aserradero industrial pues allí desde 1837, por iniciativa de Elbers, se empezó la construcción de barcos de madera diseñados para enfrentar a las bajas del caudal de agua del río Magdalena en épocas de sequía, actividad que apresuró la reapertura del puerto. Con la apertura de las actividades portuarias brotan las semillas del desarrollo porque se dejó de ver a Barranquilla como ese paso obligado del transporte fluvial a vapor que movilizaba los productos de exportación como el tabaco y luego el café. Con la construcción del ferrocarril del Atlántico ${ }^{7}$, en 1871, y el traslado de la Aduana Nacional, en 1872; se consolida Barranquilla como urbe de gran importancia en la costa Caribe colombiana, por ello, este asentamiento inicia un crecimiento urbano cuyo ritmo se acelera a la velocidad en que aumenta el comercio marítimo internacional. Las exportaciones; actividad comercial, nueva; conectan a la nación con los centros industriales y comerciales del mundo, por lo tanto, convierte este punto portuario en una conexión cultural con la civilización europea y estadounidense pues, a su vez, es el puerto el que alberga a sus inmigrantes que vienen a invertir en las exportaciones con el ánimo de monopolizar ese naciente mercado y, por tanto, apetecible para el capital foráneo.

Fue así, como la iniciativa privada impulsa el desarrollo de la municipalidad para ello: en 1877 se instala la primera fábrica de jabones en Barranquilla a la que se le llamó "La Española", en 1880 se inaugura el acueducto, en 1885 se establece la concesión del alumbrado público, en 1890 con el tranvía ${ }^{8}$ aparece el transporte urbano de pasajeros (Ospino Contreras, 2003).

$7 \quad$ El ferrocarril del Atlántico, en sus inicios tuvo una extensión de 10 kilómetros que facilitó la comunicación entre Barranquilla y Puerto Sabanilla; fue luego ampliado en cinco kilómetros hasta llegar a Puerto Colombia.

8 La Barranquilla Train Way poseía para el servicio, dos locomotoras que remolcaban tres carros de pasajeros cada una, y el recorrido abarcaba una distancia de cinco millas. Pero la ciudad aún no estaba preparada para las locomotoras ya que en su recorrido era muy común que estas crearan incendios en las edificaciones pajizas existentes a su paso lo que obligó a suspender el servicio a través de las locomotoras y esos carros pasaron a ser jalonados por caballos. 


\subsection{La ciudad del ciclo monopolista del capitalismo.}

La dinámica acelerada, de transformación tecnológica y científica, del sistema capitalista forjó la siguiente etapa de la ciudad, en este espacio la tierra rural estaba monopolizada y la poca que quedaba le pertenecía a los campesinos y, por lo tanto, eran tierras subproductivas dada la poca tecnificación de la actividad agrícola. Los obreros de la tierra fueron estimulados en una nueva fuente de energía: el petróleo; que acarreó en primer lugar la migración del campo a la ciudad y en segundo lugar una nueva forma de organización de la producción: la producción en serie, en masa o en cadena más conocida como fordismo ${ }^{9}$, y desarrollada con éxito en la industria automovilística, seguida de la generalización de la energía eléctrica y sus derivados; que estimuló a los constructores a iniciar un intensivo proceso de expansión urbana que llevó a la municipalidad hasta los límites de los municipios más cercanos desarrollándose las primeras manifestaciones de lo que hoy llamamos áreas metropolitanas (Castells, 1976).

El proceso de desarrollo y consolidación urbana de Barranquilla, continuó a lo largo del siglo XX, con momentos de auge y de decadencia, y se considera que ha pasado por cuatro etapas, caracterizadas cada una de ellas por el factor económico fundamental que las genera, sin que se pretenda señalar que este factor sea el único que interviene en el proceso de su aparición.

Estas etapas son:

1. Desde la Constitución de 1886 hasta la depresión de 1929: el auge de Barranquilla impulsado por el Comercio Internacional

2. Desde 1930 hasta 1958: el impulso del proceso de industrialización

3. 1958-1990: el estancamiento de Barranquilla

4. 1990-2005: La incidencia de la globalización.

\subsection{Desde la Constitución de 1886 hasta la depresión de 1929: el auge de Barranquilla impulsado por el Comercio Internacional}

Con la nueva Constitución, que implementó en 1886 el Estado unitario de derecho, se esperó, quizás, que en el desarrollo de las nuevas normas constitucionales se regulara lo relativo a la expansión urbana, pues el tema de la construcción, por lo menos de obra pública, ya forzaba una oportuna intervención administrativa estatal en procura de la mejora de los controles adoptados del sistema escribano colonial, que fueran ratificados por la república desde 1825 con la Ley orgánica del poder judicial llamándole "derecho de registro" 10 a la precaria herramienta que servía como control público de la limitación a la propiedad inmobiliaria ya sea como censo hipotecario o como registro de las órdenes judiciales de embargos.

9 Con el control de esta forma de producción hizo que los capitales se concentraran en unos pocos; es decir, nace el monopolio capitalista

10 Tomado de la reseña histórica presentada por el Servicio Autónomo de Registros y Notaría del Ministerio del poder Popular para las Relaciones Interiores y Justicia del Gobierno Bolivariano de Venezuela, disponible en http://www.saren.gob.ve/?q=inf_historia 
Al no ser declarada inexequible, con la Constitución de finales del siglo XIX, se le extendió la vigencia a la Ley del 11 de mayo de 1825 que a través de la iniciativa reglamentaria del ejecutivo dispuso de una oficina estatal: la del registro público (hoy conocida como Oficina de Registro de Instrumentos Públicos), como herramienta censal de las edificaciones legales a las que se les aplicaría avalúo y con base en ellos, el cobro de un impuesto predial; fue por ello que la disposición del uso del suelo y la planificación de la ciudad, como insumos del proceso de crecimiento urbano fuera en la costa Caribe colombiana muy similar a las otras regiones del país.

Ospino Contreras, encuentra datos complementarios extraídos del primer plano de la naciente ciudad de Barranquilla que fuera levantado por Cayetano Moreno y David Granados, en $1897^{11}$; en esta representación arquitectónica se deja constancia que Barranquilla se extendía sobre 386.47 hectáreas que albergaba a 4120 viviendas, de estas viviendas el 57,32\% constituyen barrios pobres como lo son barrio Chiquinquirá y barrio Rebolo, en el suroriente; el barrio San Roque y barrio Abajo, en el nororiente ${ }^{12}$.

Pero mientras la proximidad del río atrae a la izquierda, a los barrios opulentos, el enjambre humano se extiende sin cesar hacia la llanura derecha, mezclándose las cabañas de paja con las pobres viviendas diseminadas por la campiña rojiza, viviendas cada vez más pobres y diseminadas a medida que se acercan los cementerios. (D’Epagnanat, 1971)

La planificación de la ciudad, en la Colombia de inicios del Siglo $\mathrm{XX}^{13}$; fue relegada, entonces, a los particulares; pero, como era de esperarse a la administración le correspondía la afectación de terrenos a los constructores, la autorización de construir y hasta, a veces, la construcción de los espacios públicos esenciales: plazas y parques, accesos peatonales o vías para carruajes y la infraestructura de servicios públicos. Es por ello que la expansión urbana fue generada desde dos fuerzas opuestas, que interpretaron la urbanización de manera contraria: los que vieron en edificar una actividad legal que servía como fuente de ingresos estable, y los que se interesaron en construir de manera desordenada (pirata) e ilegal, y que levantaron paredes por instinto en las goteras de la municipalidad.

Sánchez Bonnet (2003), señala que, en 1916, se dio registro a la primera aparición de una gran invasión en la ciudad de Barranquilla, donde los usurpadores fueron forzados a desplazarse al convertirse en damnificados de las inundaciones de ese año, pues el aumento inesperado de caudal del río Magdalena sorprendió a todos;

11 Ver Plano 3

12 Los datos sobre el número de viviendas en los años 1872 y 1896 se tomaron del trabajo que el historiador Sergio Solano publicó en "Barranquilla vista por su alcalde 1872" un recuento histórico publicado por el Diario del Caribe el 8 de mayo de 1988 y que fuera citado por Jorge Conde en "Desarrollo de Barranquilla 1871-1905" y en "Historia General de Barranquilla" publicados en la revista sucesos de la Academia de Historia de Barranquilla en el año de 1997

13 Ver Plano 4. 
por lo tanto, la movilización humana llegó a la pujante Barranquilla en busca de un albergue temporal que rápidamente olvidaron, sobretodo, porque la ciudad les brindaba comodidades que el campo no ofrecía: servicios públicos de agua, luz, transporte y la expectativa de una jornada de trabajo de ocho horas que comparado con las del campo eran mucho más atractivas, tal vez por ello, se dieron a la tarea de ocupar de forma definitiva las seis manzanas con las que el asentamiento dio nacimiento al barrio Montecristo.

Ese tipo de construcción no se registraba en las oficinas municipales y se caracterizaba por usar los elementos más tradicionales: muros de cartón, bajareque, madera y a veces en barro; el techo dependía de las capacidades económicas tanto de quien construía como de quien fuera a vivir allí, por ello, se encontraron mayormente de paja, seguidas de latas o de caña y tablas; la construcción pirata no fue otra cosa que una tendencia difícil de controlar, pues las autoridades locales no le prestaron la atención requerida a este fenómeno; las prioridades de la alcaldía se centraban en el posicionamiento de la urbe, en implementar, en su pequeño y gobernable territorio, aquellos elementos, instrumentos y sistemas que hiciera agradable la estancia en su municipio: telégrafo, redes eléctricas, acueducto, servicio penitenciario y sanatorio, entre otros.

El primer tercio de la centuria pasada estuvo demarcada con el impulso de la construcción en zona urbana que se rezagó abruptamente hacia la década de los años treinta. El impulso tuvo causa en tres situaciones socio-económicas: por una parte la expedición de la Ley 46 de $1918^{14}$ que desarrolló la iniciativa gubernamental de otorgar recursos financieros para construcción de vivienda obrera (vivienda digna, salubre e higiénica - para combatir la tuberculosis-) (Saldarriaga Roa, 1996); por la otra parte, el auge de las inmigraciones, la mayoría de procedencia europea y su área de influencia, que huían de los efectos devastadores y consecuentes de la primera guerra mundial (1914-1918) por lo que vieron en Colombia un distante destino que le brindaría seguridad a la inestabilidad política, económica y social vivida en sus países; y por último, el incremento de las exportaciones de las cargas de café con destino a Estados Unidos y Europa. Este aumento hizo que, para la década de los años veinte, se saturara la conexión de quince kilómetros de vía férrea, que comunicaba a Barranquilla con Puerto Colombia ${ }^{15}$; ya que la locomotora bajaba café y subía con los productos importados al país desde el hemisferio norte; la solución para salir de este atolladero fue la construcción del puerto de Buenaventura, en la

14 La ley 46 disponía de la siguiente manera el recaudo para esta vivienda obrera "todo municipio que fuese mayor a 15.000 habitantes debe destinar el $2 \%$ del presupuesto a la construcción de las viviendas obreras, las cuales deberán cumplir los requisitos establecidos por las direcciones de higiene de cada municipio. Este dinero será recuperado por el impuesto establecido del $6 \%$ de valor equivalente del costo y un agregado del $4 \%$ del mismo valor, lo cual sería pagado por el habitante de esta misma población.(Ferez Santander \& Feres, 2008).

15 Puerto Colombia es el puerto fluvial donde llegaban los barcos de vapor que bajaban del río Magdalena 


\section{Costa Pacífica.}

Estos tres fenómenos crecieron la urbanización de Barranquilla, pues la villa pasó de 40.000 habitantes, censados en 1900, sobre 30 calles y 24 carreras que integraban una extensión de 450 hectáreas de terreno urbano (Ospino Contreras, 2003) a, en 1928, una población aproximada de 140.000 habitantes sobre 80 calles y 50 carreras que formaban ahora 1028 hectáreas de tierra; ahora en cuanto al tema de la construcción legal se pasó de expedirse 10 licencias anuales para el año de 1918.

Sánchez Bonnet (2003), señala que para 1922 se deja de lado la edificación predio a predio para dar paso, a la construcción de la primera urbanización que ocuparía el 55.45\% del área total de la expansión de la ciudad ${ }^{16}$, barrio que se levantó con destino a cubrir la demanda de vivienda para la elite barranquillera ${ }^{17}$ a la que se le llamó: Barrio el Prado ${ }^{18}$ (García Pacheco, 2007).

Para 1924, la administración otorgó 161 licencias anuales, en 1925 con la creación de la Empresas Publicas Municipales de Barranquilla cuyo nacimiento se debió a la expedición de las leyes 25 y 27 de 1921 fue el impulso de una tendencia que en comparación con la del año anterior creció la construcción casi al doble y fue así como en 1925 se habilitaron 257 construcciones legales, esta disposición de crecimiento se mantuvo también para el año de 1926 pues en este periodo se expidieron 453 autorizaciones-año. Superada la primera mitad de la década de los años veinte del siglo pasado, fueron emitidas 613 permisos de construcción que ampararon sólo el año de 1927, pues en este año la firma estadounidense Electric Bond and Share compró la vieja planta de la ciudad que pertenecía a la familia Obregón y la modernizó y amplió su capacidad de 4478 caballos de potencia a 11000 y con ello el estadounidense William Laad fundó la Compañía General de Urbanizaciones con la cual dio termino a la mega obra del barrio El Prado y junto a él levantó el barrio Boston (al costado sur del barrio El Prado), ya para 1928 esa tendencia de ascenso se estabilizó en un número de licenciados que no superó las 669 construcciones legales y por último en el año final de la década de los años veinte; es decir, en 1929, se expidieron un total de 1002 amparos oficiales para construir de manera coordinada con la intervención de la administración municipal. (Férez Santander \& Feres, 2008). En este año último de la década de los años veinte se autorizó la construcción de

16 Ver Plano 5

17 El barrio El Prado está ubicado al noroccidente de la ciudad, ya sabemos que el sur oriente era y es la zona deprimida de Barranquilla; esta zona fue escogida por el estadounidense Karl Parrish, como urbanizador para llevar su proyecto por buen camino convenció a Manuel de la Rosa (propietario de la finca El Prado) este megaproyecto fue levantado entonces por la urbanizadora Parrish\& Cía. el cual se ubicó a continuación del barrio las Quintas (se llamaba quintas porque las casas que allí se construyeron pertenecían a los más pudientes de Barranquilla y su extensión era propia de parcelas de más de $3000 \mathrm{~m}^{2}$ ) y del camino a La Playa (hoy carrera 50) sobre los terrenos más altos de la planicie, cuya vista da al río y a la sierra nevada de Santa Marta.

18 Ver Plano 6 
barrios como Las Delicias, Olaya, El Recreo ${ }^{19}$ y de manera paralela las invasiones que constituirían los barrios de El Valle, Montes y San Felipe. Es oportuno dejar en claro que estos números corresponden a las cifras oficializadas, como ya se dijo, la construcción ilegal superó estas cifras, y por no llevar un control adecuado en la construcción, su censo no fue posible determinarse con certeza, por ello se especula que dicha actividad le dio a Barranquilla ese aspecto de ciudad ordenada administrativamente pero desordenada en su quehacer urbanístico en algunos apartes de la ciudad.

\subsection{Desde 1930 hasta 1958: El impulso de una ciudad a través del proceso de industrialización}

Ahora, en cuanto a la parálisis de la actividad constructora que se presentó desde principios de la década de los treinta, tuvo directa relación con el congelamiento de los préstamos de la banca estadounidense como medida para contrarrestar la crisis económica de 1929, que contrario a las circunstancias presentadas en los 20 paralizó los procesos de construcción que venía en aumento constante año a año, así lo observa el historiador Férez al fundar su argumento en que para el año de "1933 cuando dicha disminución fue evidente, solo se adquirieron durante el año 95 licencias de construcción, manteniendo un costo de avalúos menor que el de 1929".

Pero esta situación no duraría mucho, gracias a la intervención estatal, que para el año de 1931 crea el Banco Central Hipotecario con el objeto societario de dar la financiación inmobiliaria que se requería para superar la crisis del sector de la construcción y, por ende, de los empleos directos e indirectos que se alimentaban de esta actividad y fue por ello que en primer lugar se financió, como prueba piloto, al sector agrario extendiendo, prematuramente, su objeto fundacional para impulsar la economía local a través de créditos hipotecarios sobre vivienda urbana. Estos créditos no sólo fueron otorgados y amparados por el Banco Central Hipotecario $(\mathrm{BCH})$ sino también con los recursos del Instituto de Crédito Territorial (ICT) creado en 1939 para apoyar al BCH.

Con la participación del Instituto de Crédito Territorial (ICT); para el mejoramiento de vivienda, dignificación de la calidad de vida $\mathrm{y}$, por lo tanto, el mejoramiento del aspecto del sur de la ciudad; se logró que las invasione ${ }^{20}$ se transformaran en humildes barrios obreros; hacia el norte el ICT realizó dos urbanizaciones para los empleados de la clase media, esos fueron los barrios Altos del Prado y Boyacá, urbanizaciones que fijaron los límites del centro de la ciudad y la entrada a los barrios de la clase alta $^{21}$.

19 Los barrios Las Delicias y Olaya fueron edificados por Salcedo Ramón \& Cía. El barrio El Recreo fue desarrollado por Francisco Insignares.

20 Para inicios de la década de los años cincuenta, se levantaron las invasiones que conformarían los barrios La Ceiba y la Sierra; donde La Ceiba fue conocida por operar allí la zona de tolerancia de la ciudad. 
Paralelo a esta situación, Barranquilla, desde la década de los años veinte, atraviesa por una crisis portuaria pues la línea férrea que la conectaba con Puerto Colombia se congestiona con el aumento de cargas de café para exportar y de los productos importados que el tren llevaba hasta Barranquilla. La solución para salir de este atolladero fue la construcción del puerto de Buenaventura, en la Costa Pacífica; puerto que para la década siguiente, la de los años treinta, superó a Puerto Colombia en número de las exportaciones en sacos de café y los productos importados. Buenaventura despuntó día a día la actividad portuaria de Barranquilla, ya que contaba con instalaciones más amplias, dotadas de equipos modernos e implementada con lo necesario para recibir embarcaciones de gran calado; lo anterior obligó a la clase dirigente barranquillera para que firmara el contrato con la empresa ULEN, cuyo objeto contractual se fijó para la adecuación de los tajamares ${ }^{22}$ que en su conjunto formarían lo que hoy se conoce como el canal en el sector de Bocas de Cenizas, desembocadura del río Magdalena, lo anterior con el fin de facilitar la navegación en épocas de sequía y así permitir el ingreso de los buques hacia el nuevo puerto, el que se levantaría dentro de los límites urbanos de la ciudad de Barranquilla. Estas obras dieron inicio desde 1925 y culminaron en 1939 y dieron valorización a los terrenos adyacentes donde se ubicaría la zona franca y la zona industrial en la isla de Barranquillita ${ }^{23}$.

Con la puesta en marcha de las obras de mejoramiento del Puerto, Barranquilla se convirtió en un centro industrial en auge, fueopacado por los problemas de la zona industrial mal prevista por la administración barranquillera por lo que las pocas industrias que se aventuraron a instalarse allí cerraron por el problema con el alcantarillado sumado a lo anterior resulta que las expectativas de crecimiento industrial sólo duraron hasta que el comercio desarrollado por Buenaventura se impusiera, punteara y opacara la actividad barranquillera como foco portuario; fue así como el interior prefirió a Buenaventura quedándose en el rezago Barranquilla, por ello el impulso de desarrollo dado por la industria se apagó en 1947.

Para este año, 1947, el gobierno central trató el tema "sobre fomento del desarrollo urbano del municipio y se dictan otras disposiciones" con la ley 88 , del 15 de diciembre de 1947; a través de esta ley se define, por primera vez, el área urbana como concepto y señaló el artículo 1 de esta ley que el área urbana es aquella "extensión comprendida dentro de la nomenclatura legal correspondiente

22 Al término de la construcción de estos tajamares en Bocas de Cenizas, se invadió los terrenos donde operaba el campamento de la constructora Parrish \& Cía. y que se conocía como campamento Las Flores asentamiento que dio nacimiento al barrio que lleva su mismo nombre: al que hoy se conoce como Barrio Las Flores.

23 Barranquillita es la isla pantanosa frente al nuevo puerto fluvial, el que se construyó sobre el río en el área urbana de Barranquilla; en Barranquillita se tenía prevista la zona industrial y su desarrollo no se logró en debida forma por presentar problemas en el sistema de alcantarillado pues en época de lluvias el sistema quedó más bajo que el caudal del río lo que produjo el rebosamiento de las aguas 
o la determinada por los concejos municipales por medio de acuerdos"24 (Solano, Ensayos fabriles y estructura ocupacional en Barranquilla a finales del siglo XIX, 1989)

En la década posterior (1947 a 1957) Barranquilla crece a causa de la industria de la construcción respaldada por la nueva bonanza, la explosión de las exportaciones de café que se dieron en este periodo; la ciudad experimenta entre los años 1947 y 1957 una década de auge comercial sin precedentes, como resultado de la política de comercio exterior liberal del presidente Laureano Gómez y que los importadores de Barranquilla aprovecharon muy bien ${ }^{25}$. De la misma manera los exportadores de café viven el último auge por el aumento de los precios y en parte también de la cantidad exportada. Durante esta "prosperidad de milagro" de los años cincuenta, rebrota nuevamente con mucha fuerza la idea del progreso, que a pesar del decaimiento de la industria, el aumento inusitado de las importaciones produce la ilusión de que la ciudad retomaba nuevamente el impulso de los años veinte y treinta. (Solano, Comercio, transporte y sociedad en Barranquilla durante la primera mitad del siglo XIX, 1989)

El año 1958 fue crítico para la naciente ciudad porque se estanca dado el decaimiento del café y, por lo tanto, de la construcción, pues la expansión urbana va de la mano junto al crecimiento económico, además por las malas políticas de comercio exterior ${ }^{26}$ adoptadas por el Frente Nacional que hicieron que esta ciudad, para la fecha, se retrotrajera luego de que se había expandido hasta casi un cincuenta por ciento de lo que es hoy Barranquilla, estos datos fueron precisados por el profesor Ospino Contreras bajo el siguiente tenor: "ya para ese entonces la ciudad abarcaba 1881,85 hectáreas, es decir, un 43,48\% del área que ocupa en la actualidad." ${ }^{27}$.

Esta prosperidad de milagro se acabó de manera repentina en 1957 y 58 cuando se desarmó el cuadro favorable. Las divisas del país se agotaron, el Frente Nacional refuerza el centralismo de la capital, cambió la política exterior con limitaciones

24 Sólo hasta 10 años después de sancionada la Ley 88 de 1947 la administración barranquillera decide levantar el plano de su área urbana y lo inserta en el Documento al cual llamaron el Plan Regulador de 1957. Ver Plano 9. Este Plan Regulador articulaba la ciudad a través obras públicas y proyectos viales que condicionaban la utilidad de los predios aledaños que quedaban afectados por el plan de usos del suelo o estatuto urbano y que pese a sus sucesivas modificaciones duró vigente hasta 1993 cuando la administración distrital expidió el Decreto 654 de 1993, al que llamó: "Estatuto de Usos del Suelo del Distrito de Barranquilla", modificado por el Decreto 572 de 1994.

25 Ver el auge comparando los Planos 8 y 9.

26 La industria barranquillera se desacelera a causa de las políticas proteccionistas del producto nacional le hacen perder a los comerciantes de la ciudad la competitividad y ventajas que se tenían. (Meisel Roca \& Posada Carbó, Por Qué se disipó el dinamismo industrial de Barranquilla, 1993)

27 Si examinamos un poco más en detalle estas 2881,85 ha., se encontramos que: 487,83 ha. corresponden al crecimiento predio a predio del centro histórico, conformado por barrios como Rosario, San Roque, Abajo, Chiquinquirá y Rebolo, que se desarrollaron entre los siglos XVIII y XIX; 269,48 ha. $(9,35 \%)$ fueron producto de invasiones; 346,05 ha. (12\%), fruto del loteo sin servicios públicos; $1.778,49$ ha. corresponden a las urbanizaciones iniciadas en 1922 como barrio El Prado, Boston, Bella Vista, Las Delicias, Olaya. 2881,85 ha. es el total de la suma de las anteriores cifras. (Ospino Contreras, 2003). 
drásticas a las importaciones y el desarrollo de la industria agotaba sus posibilidades en toda América Latina. De esta manera la ciudad inicia los años sesenta con una crisis industrial y comercial al mismo tiempo, que se ve agravada por la inmigración masiva de campesinos de las regiones aledañas a la ciudad que hacen más grave el desempleo estructural y surgen los tugurios con sus secuelas de caos urbano y deficiencia de los servicios públicos. (Solano, Barranquilla a finales del siglo XVIII y comienzos del XIX, 2008).

\subsubsection{8-1990: El estancamiento económico de Barranquilla y las estrategias para salir del aletargamiento. La problemática Conurbación}

Con el inicio de los 16 años del Frente Nacional (1958-1974) nacen nuevas prácticas políticas: el clientelismo (la compra de votos), el cambio de lotes por votos y las invasiones ${ }^{28}$, promovidas por políticos, dieron constitución a barrios como 20 de Julio y San Nicolás (Meisel Roca, Rezago relativo y creciente integración 19501994, 1994).

Con la crisis energética de los años setenta este sistema colapsa, y evoluciona ya no de la agricultura a la industria pues se pasa de productos manufacturados a la prestación de servicios, esta transformación económica permeó a la sociedad por lo que en consecuencia los gobiernos reaccionaron, y para superar aquellos efectos, implementan un "nuevo modelo de producción más flexible": la acomodación del espacio a las necesidades del sistema capitalista, ideario nacido por iniciativa de las empresas multinacionales de servicios que ven en este nuevo sistema la amalgama para imponer normas, costumbres comerciales y el desmonte de aranceles aduaneros como condición para invertir. A este proceso de eliminación de barreras, para abaratar costos de producción, se le denominó como globalización, fenómeno que hace girar a la ciudad que le dio cabida al monopolio capitalista para dar paso a la megaciudad"29 "las ciudades globales" (Sassen, 1991).

Con la estabilización del Estado, ese fundado en 1886, fue posible pasar de país agrario a industrial, allí hay que destacar los esfuerzos de Olaya Herrera y López Pumarejo por robustecer la precaria economía gravemente golpeada por la crisis mundial de la década de los veinte, esa fue la oportunidad para industrializar una nación agraria por convicción, el impulso de la industria citadina permitió crear puestos de trabajo para mitigar las oleadas migratorias de campesinos que había incrementado las invasiones y pobreza en los municipios capitales de departamento, donde como

28 Ver Plano 10

29 En América Latina sobresalen como megaciudades: Ciudad de Méjico, Sao Paulo, Río de Janeiro y Buenos Aires. Las ciudades Globales se caracterizan por poseer sedes de los principales bancos mundiales, sedes de compañías de seguros, de centros de investigación y de empresas de producción de tecnologías de punta; es decir, controlan las finanzas internacionales y, por lo tanto, estas ciudades están dentro de la red mundial de megaciudades (Aguilar, 2002). 
ya se vio el área metropolitana de Barranquilla también se afectó, en su derredor se trataba de cambiar la cara de cinturones de miseria liderada por el campesinado desplazado y gobernada por la autoconstrucción desmedida, sin planificación, sin política de urbanística costumbre que aún en nuestros días se evidencia a diario; para pasarla a la de suburbios edificados, bajo iniciativa y patrocinio del gobierno central, para esa nueva clase: la obrera, manteniendo la ciudad su centro motor. La primera evidencia de la problemática conurbación se estructura de los cinturones pobres que crecían desde el contorno barranquillero hacia sus vecinos y en desmedida desde los municipios cercanos hacia el centro municipal capital de departamento; esta realidad estaba presente en todas las ciudades capitales de departamento en donde los códigos socioculturales del modelo económico se imponían sobre la lógica de la planeación urbanística adecuada destinada para las periferias no desarrolladas (Echevarría Ramírez, 2004).

La Barranquilla de los años veinte que fuera receptora de migrantes extranjeros con suficientes recursos para impulsar el comercio y que expandieron al municipio al ritmo en que ascendieron sus ingresos ya no volvería pues, ahora, desde 1958 y por los 25 años siguientes la ciudad sería el destino de migrantes del interior desplazados del campo a la ciudad que llegaban en ruina en busca de un mejor porvenir y que 11000 de ellos se convierten en vendedores ambulantes y con estos ingresos construyeron sus ranchas sobre terrenos de otros y generaron un nuevo problema los cinturones fuertes de pobreza, que para $1983^{30}$, la aglomeración de viviendas subnormales construidas en las invasiones ascendieron al 60\% (unas 1403,21 ha.) del área de expansión de la ciudad, a su alrededor estaban las urbanizaciones populares desarrolladas en los años setenta bajo la política "ciudades dentro de la ciudad" que desarrollaron barrios como El Silencio, Los Trupillos y El Campito; la extensión de los barrios populares llegaba en cifras oficiales al 19\% (unas 444,35 ha.) del glose total de la ciudad (Instituto de Crédito Territorial, 1976). Durante este periodo de tiempo se expidió la reforma constitucional de 1968, con la cual se le dio nacimiento a las áreas metropolitanas en Colombia y que fueran desarrolladas legalmente con la Ley 61 de 1978: "Ley orgánica de desarrollo urbano" y nació Barranquilla como área metropolitana con la ordenanza 028 del 11 de diciembre de 1981, que se fundamentó en el Decreto-Ley 3104 de 1979, ordenanza que constituye esta área con los municipios de: Barranquilla, Puerto Colombia, Soledad y Malambo, 17 años después, en 1999, se integra Galapa y se crea la oficina del Área Metropolitana de Barranquilla a la que se le encargó la coordinación de un "desarrollo armónico e integrado" como las vías y el mejoramiento de los servicios públicos domiciliarios de los municipios bajo su jurisdicción (Área Metropolitana de Barranquilla, 2004, p. 3). En general la dirección de la Oficina del Área Metropolitana ve su propia actuación y efectividad muy crítica y objetivamente: crisis financieras e instituciones permanentes (algunos aportes de los municipios no han sido cancelados o han sido 
apenas cancelados parcialmente ${ }^{31}$ ) así como la posición hegemónica de Barranquilla con sus "efectos claramente negativos" obstaculizan el "desarrollo metropolitano". (Mertins, Estudios Urbanos - regionales desde el caribe: el crecimiento "moderno" espacial - urbano en Barranquilla: ¿Planeación pública - oficial o manejo del sector privado?, 2007)

Para dar continuación a la apertura de este capítulo, se basa en los escritos del profesor Efraín Llanos Enríquez, en especial la de la producción de investigación titulada "Proceso de transformación espacial de Barranquilla en el Siglo XX", publicada en 2007 a través de artículo bajo el mismo nombre en la revista "Perspectiva Geográfica", Vol. 12, donde sustenta que los procesos de transformación espacial que han sufrido las ciudades capitalistas, y que a partir de la Revolución Industrial la adaptación de los espacios que hace el capitalismo para garantizar el proceso de acumulación de riqueza se basan en diferentes fuentes de información: cartográficas, históricas, estadísticas y económicas, entre otras para terminar de acuerdo con los postulados de Borja y Castells (1997): "Junto a la concentración direccional en los centros de las grandes metrópolis, se ha constituido una red dispersa y articulada en la gestión de los servicios, localizada en las periferias metropolitanas, así como en centros metropolitanos regionales de menor entidad". Por lo que del mismo modo, se ha generado un patrón urbano policéntrico y una expansión de las que lleva a incorporar gran parte de las zonas rurales, lo cual conlleva a que los límites entre estas dos zonas se hagan cada día más difusos. A esta dinámica de las megaciudades, Aguilar (2002) la denomina como las periferias metropolitanas expandidas.

Con el Acuerdo Metropolitano No. 4 de 1982, los integrantes del área metropolitana de Barranquilla adoptan el Plan Integral de Desarrollo Metropolitano con el cual se dio inicio al proceso de planificación del área como ciudad metropolitana. Acuerdo que sirvió como fundamento para la construcción, en 1986, del estadio Metropolitano al sur de la ciudad de Barranquilla y en límites con el municipio de Soledad; esta construcción facilitó el poblamiento de sus alrededores que para el final de este periodo (fin de la década de los ochenta) el proceso de metropolización se consolida con la conurbación total de Barranquilla sobre el municipio de Soledad. Para 1986 Barranquilla estaba inmersa en una crisis de servicios públicos: el agua potable llegaba por acueducto sólo al $55.7 \%$, los demás tendrían que comprar el líquido a los carrotanques que la distribuían diariamente, el alcantarillado también

31 Mediante el Parágrafo Único, del Artículo 17 de la Ley 14 de julio 6 de 1983, a través del cual se creó la sobretasa del 1 x 1.000, sobre el avalúo catastral, para las propiedades situadas dentro de la jurisdicción de cada área metropolitana, con el fin de dotarlas de recursos permanentes que les permitiesen atender los diversos programas a favor de los municipios que la integran, durante la primera década de funcionamiento del Área Metropolitana de Barranquilla, no se implementaron los mecanismos eficaces para hacer cumplir esta disposición y fortalecer así su presupuesto. Posteriormente, el Decreto-Ley 1333 de 1986, Código de régimen municipal, reafirma la vigencia de la normatividad metropolitana, dando expresas facultades a la autoridad metropolitana para el incremento hasta un tope máximo del recaudo del 2 x 1.000 sobre el avalúo catastral. 
era deficiente pues cubría al 48.9\% de las casas familiares ${ }^{32}$; esta crisis empeoraría para las empresas públicas municipales de Barranquilla la cual no fue capaz de dar abasto con las necesidades locales y, por lo tanto, con las exigencias de la nueva constitución que regía para los colombianos por lo que se liquidó en 1992 creándose, en su lugar, una nueva de economía mixta, llamada Triple $\mathrm{A}^{33}$.

\section{LA MODERNIDAD DE LA REGIÓN. DE LA METROPOLIZACIÓN INSTITUCIONALIZADA A LA GLOBALIZACIÓN. 1990-2005: LA INCIDENCIA DE LA GLOBALIZACIÓN}

En el capitulo anterior se vio cómo en 1958 la naciente ciudad porque se estanca dado el decaimiento del café y, por lo tanto, de la construcción, pues la expansión urbana va de la mano junto al crecimiento económico, además por las malas políticas de comercio exterior ${ }^{34}$ adoptadas por el Frente Nacional que hicieron que esta ciudad, para la fecha, se retrotrajera luego de que se había expandido hasta casi un cincuenta por ciento de lo que es hoy Barranquilla, estos datos fueron precisados por el profesor Ospino Contreras bajo el siguiente tenor: "ya para ese entonces la ciudad abarcaba 1881,85 hectáreas, es decir, el 43,48\% del área que ocupa en la actualidad." ${ }^{35}$; pues bien, el otro impulso de migraciones originados por los desplazamientos de campesinos de se trasladan del campo a las ciudades capitales cercanas se presenta desde la década de los años ochenta y con mucha más intensidad en los años noventa (Mertins, Transformaciones recientes en las metrópolis latinoamericanas y repercusiones espaciales, 2004) estos desplazamientos fueron forzados por la guerra y los enfrentamientos entre el ejército nacional y las organizaciones guerrilleras, paramilitares y las mafias de las drogas; sobre todo de las áreas rurales de los departamentos de Sucre, Córdoba, Bolívar y el Magdalena Medio antioqueño, población que llegaría a asentarse preferiblemente en el municipio de Soledad entre 1993 y 2005. (Área Metropolitana de Barranquilla, 2004, p. 9)

Barranquilla, desde que fuera concebida bajo ese nombre, por ser la puerta de entrada y salida de productos comerciables se ha caracterizado por ser receptora de población migrante; la procedencia de estos foráneos ha impactado la economía

32 Tomado del informe, periodo 1985-1986, de las Empresas Públicas Municipales de Barranquilla, presentado a la administración central.

33 Se le conocía como Triple A por aglutinar los servicios de Aseo, Alcantarillado y Acueducto.

34 La industria barranquillera se desacelera a causa de las políticas proteccionistas del producto nacional le hacen perder a los comerciantes de la ciudad la competitividad y ventajas que se tenían. (Meisel Roca \& Posada Carbó, Por Qué se disipó el dinamismo industrial de Barranquilla, 1993)

35 Si examinamos un poco más en detalle estas 2881,85ha.se encuentra que: 487,83 ha. corresponden al crecimiento predio a predio del centro histórico, conformado por barrios como Rosario, San Roque, Abajo, Chiquinquirá y Rebolo, que se desarrollaron entre los siglos XVIII y XIX; 269, 48 ha. $(9,35 \%)$ fueron producto de invasiones; 346,05 ha. (12\%), fruto del loteo sin servicios públicos; 1778,49 ha. corresponden a las urbanizaciones iniciadas en 1922 como barrio El Prado, Boston, Bella Vista, Las Delicias, Olaya, 2881,85 ha. es el total de la suma de las anteriores cifras. (Ospino Contreras, 2003). 
de la ciudad, pues en un comienzo el impulso financiero de la urbe fue generado a consecuencia de la inversión extranjera y luego de manera negativa, caracterizada por las invasiones, los migrantes del interior, representados por aquellos desplazados pobres que del campo buscaban la ciudad y que generaron en Barranquilla graves problemas sociales, políticos, de servicios públicos y de sanidad municipal; lo anterior puede ser por la ubicación de Barranquilla casi que en sándwich en medio de Cartagena y Santa Marta, localización que le ha servido de epicentro, de núcleo, de punto focal para la aglutinación de viajeros en busca de oportunidades y que se estancan en esta municipalidad con esperanza de superar la miseria que les embarga.

En el año 1992, fue mítico para la ciudad metropolitana, por la segunda elección popular de alcaldes ${ }^{36}$ que se posesionó como burgomaestre de la ciudad: Bernardo Hoyos, además es el primer año de vigencia de la nueva Constitución colombiana: La Constitución Política de $1991^{37}$; y también porque es la primera vez que la dirigencia barranquillera se interesa en bajar los índices de pobreza en la ciudad y en desarrollar el contexto social de la nueva Constitución y por último en este año se liquidaron las empresas públicas municipales para dar paso a una nueva, saneada pero de economía mixta conocida como la "Triple A"; para este año, según datos de la oficina de Planeación Distrital los predios registrados como estratos $1^{38}$ y $2^{39}$ alcanzaban una sumatoria del $43,71 \%$ de la totalidad de los predios del distrito, para este mismo año la cobertura de servicios públicos era inadecuada (el agua potable llegaba a través de carro-tanques y no había alcantarillado, entre otros) por lo que su cobertura alcanzaba al $41 \%$ de los hogares barranquilleros; cobertura que para la finalización del periodo

36 La elección popular de alcaldes fue un suceso aprobado en 1986, su primera experiencia fue para las elecciones de 1988. Con la puesta en vigencia del Acto Legislativo No. 1 de 1986, por el cual se institucionalizó la elección popular de alcaldes, indudablemente se suscitaron cambios positivos en el manejo de la administración metropolitana, fue así como dentro de la gestión del Dr. Alberto Pumarejo Certain, primer Alcalde Metropolitano elegido por decisión popular, mediante Acuerdo Metropolitano No. 1 de 1989 se determinó la Estructura Administrativa del Área Metropolitana complementándose el alcance del Acuerdo No. 3 de 1984, y se establece una planta de cargos para el funcionamiento de la Entidad acorde con las necesidades y funciones de índole supra-municipal direccionadas bajo la responsabilidad de la Secretaria Ejecutiva.

37 Al tiempo en que se revitalizaba el papel preponderante del Área Metropolitana de Barranquilla, la Nueva Constitución de 1991, en el Artículo 319, ratifica la esencia jurídica de las áreas metropolitanas, otorgándoles la misión de programar y coordinar el desarrollo armónico del territorio bajo su jurisdicción y la racionalización de la prestación de los servicios públicos; y por ello para satisfacer sus fines Mediante el Acuerdo Metropolitano No. 01 de 1991, sancionado por el Alcalde Metropolitano, Miguel Bolívar Acuña, se incrementó al 2 x 1.000, el recaudo de la sobretasa sobre el avalúo catastral, con lo cual se dio un gran paso tan necesario para el mejoramiento de la estructura patrimonial y financiera de la Entidad, habida consideración de los trascendentales objetivos que por razón de su competencia se deberían reflejar en beneficio de los municipios integrados.

38 En el estrato 1 se amparaban 60643 predios que representan el $25.71 \%$, de un total de 236120 predios, para 1993

39 Como estrato 2 se cubrían 42430 predios que representan el $18.00 \%$, de un total de 236120 predios, para 1993 
del alcalde Hoyos se tenía un cubrimiento en servicios básicos superior al $90 \%{ }^{40}$; es decir, que estos servicios aumentaron del $41 \%$ al $90 \%$, desde luego estas metas fueron alcanzadas de la mano del plan trienal y del apoyo del gobierno nacional que con este proyecto social preparó a la ciudad para enfrentar el proceso de apertura y globalización de la política bandera del presidente César Gaviria.

Con la Ley 128 de Febrero 23 de 1994, se expide la Ley Orgánica de las Áreas Metropolitanas, cuyo objeto busca fortalecer su figura institucional, para lo cual les atribuyó el carácter de entidades administrativas en el caso de Barranquilla según el informe de este instituto colegiado cuenta con la total participación de los alcaldes de los municipios conexos, quienes hacen parte de la Junta Metropolitana, y participan activamente en materia de Planeación, obras públicas y vivienda, recursos naturales y manejo y conservación del ambiente, prestación de servicios públicos y valorización, entre otros. Estas decisiones han de ser ejecutadas por la representación legal del Área a cargo del gerente metropolitano, quien será el encargado de direccionar la acción administrativa de la entidad y de entre sus funciones básicas velar por la ejecución del Plan Integral de Desarrollo Metropolitano de Barranquilla, con el apoyo de las unidades técnicas y la interacción del Concejo Metropolitano de Planificación, organismo asesor de las autoridades administrativas del Área para los procesos de preparación, elaboración y evaluación de los planes de desarrollo.

Para tal fin fueron nombrados como Directores de la Entidad los siguientes profesionales: Dr. Pedro Celia (1992-1994), Porfirio Castillo Zamora (1994-1996), Ramsés Vargas Lamadrid (1996-1997), Armando Guijarro Daza (1998-2000), Anwar María María (2001-2003), Flor María Acuña (2004-2006), Rodolfo Bossa (2006), Anatolio Santos (2006-2007) Viviana Llinás Cepeda (2007-2008) Ricardo Felipe Restrepo Roca (2008). A través de estos se logró el impulso y constitución mediante el sistema de Concesión de La Empresa Metropolitana de Telecomunicaciones -Metrotel-, la Rehabilitación de la Avenida Circunvalar, la Reconstrucción de la Calle Murillo, la Reconstrucción de la Calle 17, Construcción de la Avenida Las Torres, la construcción de escenarios deportivos y la ejecución de obras de saneamiento básico en los diferentes municipios integrados. Consecuente con el Decreto 170 de 2001, por el cual se reglamentó el servicio público de transporte terrestre automotor colectivo Metropolitano, Distrital y Municipal de pasajeros, se constituyó a través del Acuerdo Metropolitano No. 013-01 de 2001 al Área Metropolitana de Barranquilla como autoridad única de Transporte Metropolitano en el ámbito de su jurisdicción, la cual tendrá las funciones de organización, planeación, inspección, control y vigilancia de la actividad transportadora en los municipios que la conforman o llegaren a conformarla. El Área Metropolitana de Barranquilla mediante convenio ínter administrativo suscrito con Metrotránsito asumió las funciones de autoridad de transporte masivo a partir del $1^{\circ}$. de noviembre de $2007 .{ }^{41}$

Con el actual plan de desarrollo de Barranquilla 2012-2015: “Cerrar brecha social

40 Cifras tomadas de la Encuesta Nacional de Calidad de Vida realizada por el DANE. 1993

41 Tomado de la página del Área Metropolitana de Barranquilla; vista el 25 de abril de 2010 y visible en la dirección: http://ambq.gov.co 
y abrir caminos hacia la competitividad" presentado por la Alcaldesa metropolitana Elsa Noguera, la proyección de Barranquilla deja de ser municipal, aceptado ser un municipio que traspasó sus fronteras y que necesita interactuar mas allá de Soledad, Galapa y Malambo; en este plan se trata de consolidar la puesta en marcha desde el alcalde Hoyos quien contrató la asesoría del gobierno de Barcelona para replicarlo en Barranquilla ya que se tenían muchas zonas comunes, como lo es ser Puerto, y que éste le represente el progreso de la región. Barcelona asocia a 36 municipalidades y de allí que Barranquilla desde hace cinco años haya venido insistiendo en la región Caribe, dentro del plan para la Barranquilla barcelonizada está la recuperación de la zona histórica, ello para asegurar el turismo, la Barranquilla renovada la moderna la que va de la mano con la infraestructura propia de una ciudad pujante en el comercio internacional, y el desarrollo vial a través de 3 grandes obras metropolizadas: el OUI o corredor ambiental metropolitano, la autopista metropolitana y el sistema de transporte multimodal; con esto Barranquilla quiere imponerse al puerto de Buenaventura, segundo en recepción de productos y a los pujantes y renacientes puertos de Cartagena y Santa Marta (con quienes compartió intereses comunes en la época de la independencia, buenas relaciones perdidas pero recuperables) los cuales ante la saturación y sobredemanda del Puerto de Barranquilla toman repunte en las transacciones internacionales, los cuales van en desarrollo del artículo 4 del acuerdo metropolitano 004 de 2000 que reza: "Hacer del área metropolitana de Barranquilla, el territorio más competitivo de Colombia"; es de resaltar que este esfuerzo va desde Barranquilla para integrar a sus vecinos pero falta que éstos sean consecuentes de la intención de aquél pues pese a existir directrices metropolitanas propias, comunes e idóneas para el ordenamiento territorial integrador metropolitano se llevó a cabo en junio de 2009 con la resolución 134 del Área Metropolitana de Barranquilla (AMB) un esfuerzo para revisar, ajustar y trazar nuevas políticas. Tal vez una de las dificultades del Plan Región sea conservar el sentido barranquillero, se debería generalizar el Área Metropolitana para integrar en primera medida a Santa Marta (de quien fue dependiente cuando éste fue parte de su gobernación) y su zona de influencia pues es más sencilla la vinculación individual de municipios que la colectiva en el esfuerzo Región Caribe de allí que la primera consulta no haya sido aprobada por los habitantes de esta zona, para ello sería propio que la administración de la AMB le echara un vistazo a su vecino, el área metropolitana del Valle de Aburrá, el cual por su nombre genérico ha logrado vincular a más de una docena de municipios con el firme propósito de ser la zona, el valle y no el nombre de una ciudad el área más competitiva de Colombia.

En la actualidad Barranquilla se está integrando urbanísticamente con Puerto Colombia y al terminar la construcción de magno proyecto integrado al plan maestro de una firma cementera que ahora es contratista de constructoras para que desarrollen las fases de su plan maestro denominado Riomar (Río en representación de Barranquilla y Mar por Puerto Colombia) de andenes espaciosos, espacios públicos cómodos, amplias vías, edificios modernos y dotación educativa y de salud, para la 
recreación y el esparcimiento de última generación, que va de la mano a la visionaria y moderna Barcelona. Esta conurbación hará inevitable que Puerto Colombia solicite su ingreso al AMB; nuevamente la iniciativa privada agranda los límites de la Barranquilla estatal, en esta ocasión en 1.300ha. de propiedad de Cementos Argos se construye la ciudad moderna que fusiona 700ha. del noroccidente de Barranquilla con 600 en el Sur oriente de Puerto Colombia; de esas 1300 hectáreas están en construcción las primeras 769 hectáreas, distribuidas así: 548 hectáreas que se usarán en la edificación de las unidades residenciales de estratos y usos diferentes (que van desde centros comerciales, empresariales, hoteles y campos deportivos), mientras que las 221 restantes hacen parte de las áreas de espacios públicos y ecológicos gobernados por una planeación ambientalmente sostenible y de largo alcance, previendo una estructura vial a partir de bulevares arborizados y parques verdes para la integración vecinal. El proyecto Riomar se dividió en tres grandes sectores: Lago Alto, Mallorquín y El Magdalena. El primero tiene un área de 233ha. y está destinado para vivienda de estrato alto, además de un centro empresarial. El Mallorquín es de 319ha y allí se edifican unidades de estrato medio alto. Incluye varios parques de esparcimiento, el clúster educativo; finalmente el sector El Magdalena, de 217ha. , en el que se pretenden construir unidades de estrato medio, con parque ambiental, en convivencia con la industria pesada y liviana de la zona, además de unidades comerciales; en todos habrá equipamentos de salud, vías, servicios públicos y otros desarrollos. Esta misma cementera planea edificar otras 1.300ha. que posee en su vecina Cartagena (en mediaciones de Barú); esta mega obra es sin duda el principio de una integración regional que debe aprovechar en buena medida el director del AMB y su alcaldesa metropolitana.

Y lo está logrando toda vez que Barranquilla fue categorizada en el puesto octavo entre las ciudades que conforman el continente americano por la FDI INTELLIGENCE Magazine ${ }^{42}$. Esta revista especializada en finanzas publicó un artículo llamado "Ciudades americanas del futuro 2011-2012" basado en el estudio realizado para estandarizar o darle ranking a las ciudades competitivas bajo los parámetros establecidos por seis categorías de evaluación: potencial económico, recursos humanos, relación costo-beneficio, calidad de vida, infraestructura y entorno amigable para la inversión; fue así como en la versión sajona el primer puesto del estudio lo obtuvo la ciudad de Nueva York, seguida de Chicago y Houston, luego por ciudades canadienses, Toronto y Montreal; en el chequeo subtitulado como "Ciudades latinoamericanas del futuro", primaba Santiago de Chile seguida en un cuarto puesto Bogotá y Barranquilla en el octavo. Lo anterior apunta hacía un posicionamiento estratégico no sólo a nivel regional, sino a nivel mundial y

42 Publicación especializada en inteligencia financiera, editada por el diario británico The Financial Times, publica bimensualmente con una circulación de más de 15.000 ejemplares, que han permitido que los inversionistas del mundo tenga una perspectiva global del mapa de inversión actual. Esta visible en: http:// www.fdiintelligence.com/fDi-Tools/fDi-Magazine 
Barranquilla se posiciona gracias a Pro Barranquilla, que por medio de su gestión ha logrado la atracción efectiva de inversionistas a la ciudad.

Plano 1. Plano de Barranquilla, año 1777

\section{CONVENCIONES:}

1. Primer puerto, Plaza Ujueta

2. Iglesia de San Nicolás

4. Primer Cementerio

3. Mercado Público

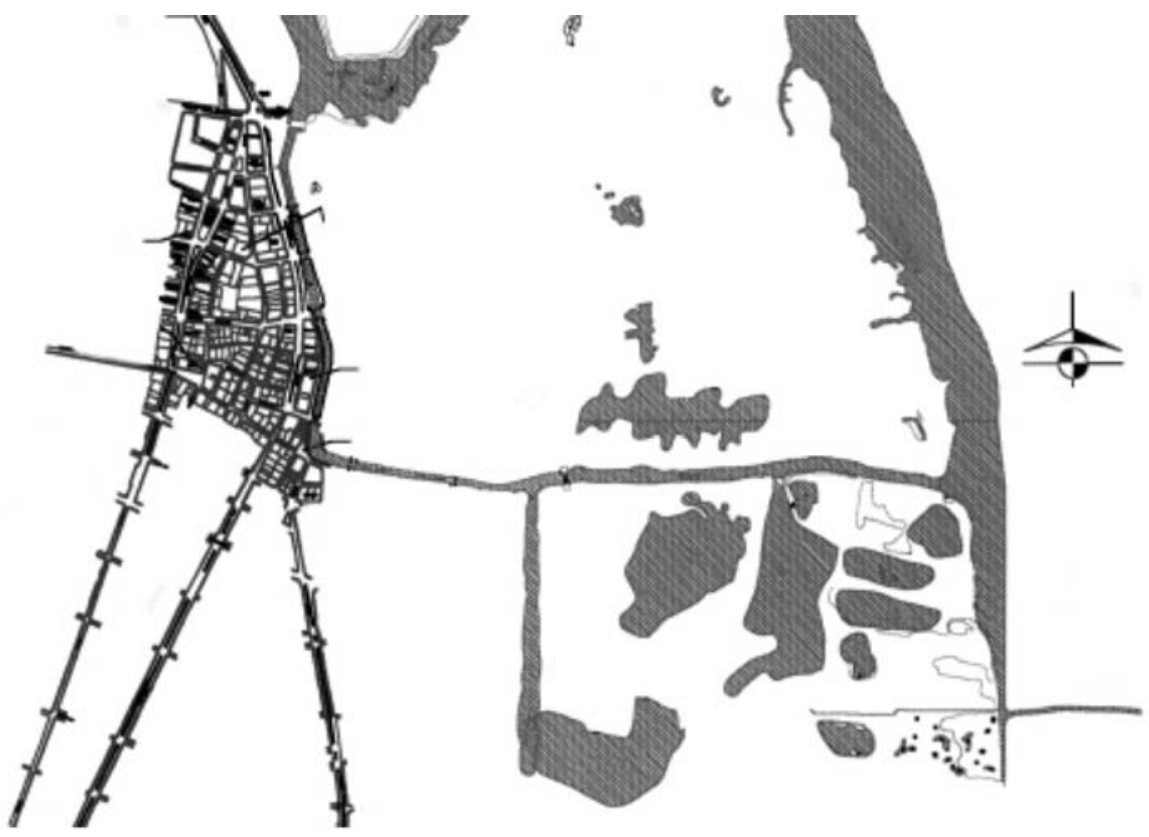

Fuente: aproximación realizada, con base en el censo de 1977, por el autor en: (Ospino Contreras, 2003) 
Plano 2. Plano de Barranquilla, año 1777

\section{CONVENCIONES:}

1. Primer puerto, Plaza Ujueta

3. Mercado Público

2. Iglesia de San Nicolás

4. Primer Cementerio

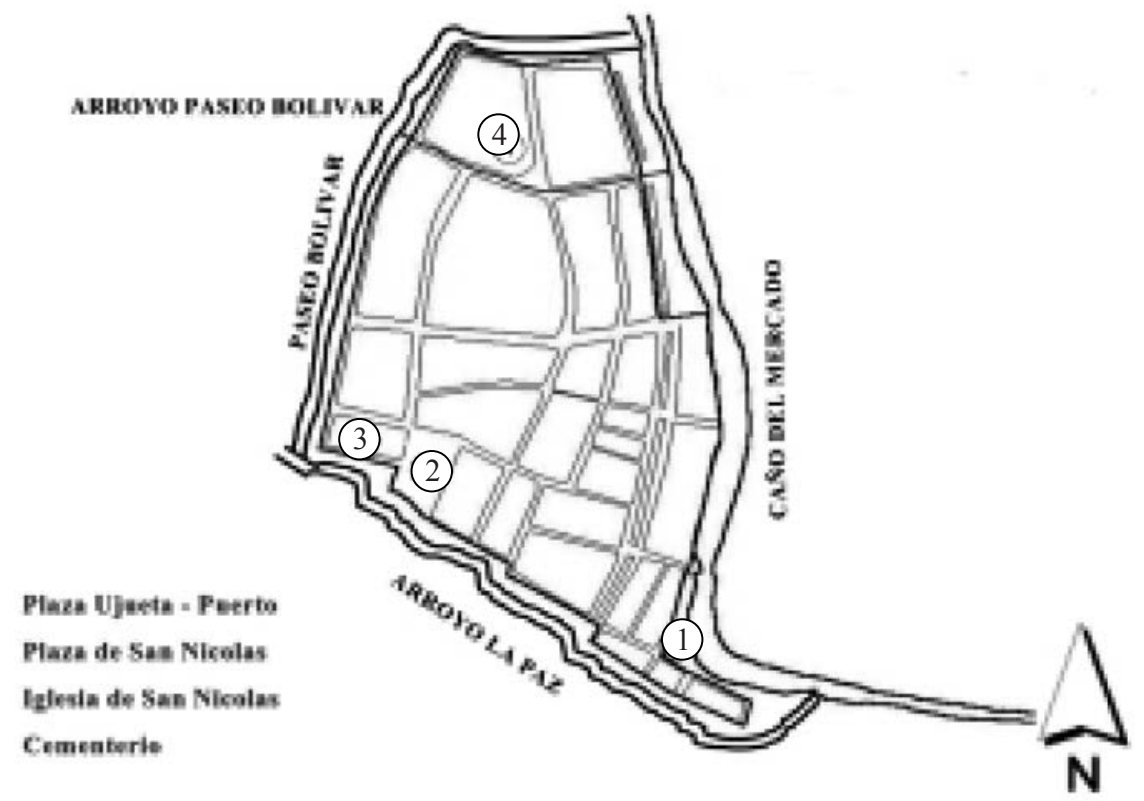

Fuente: aproximación realizada, con base en el censo de 1977, por el autor en: (Ospino Contreras, 2003). 
Plano 3. Primer Plano oficial de Barranquilla, año 1897.

Realizado por Cayetano Moreno y Darío Granados

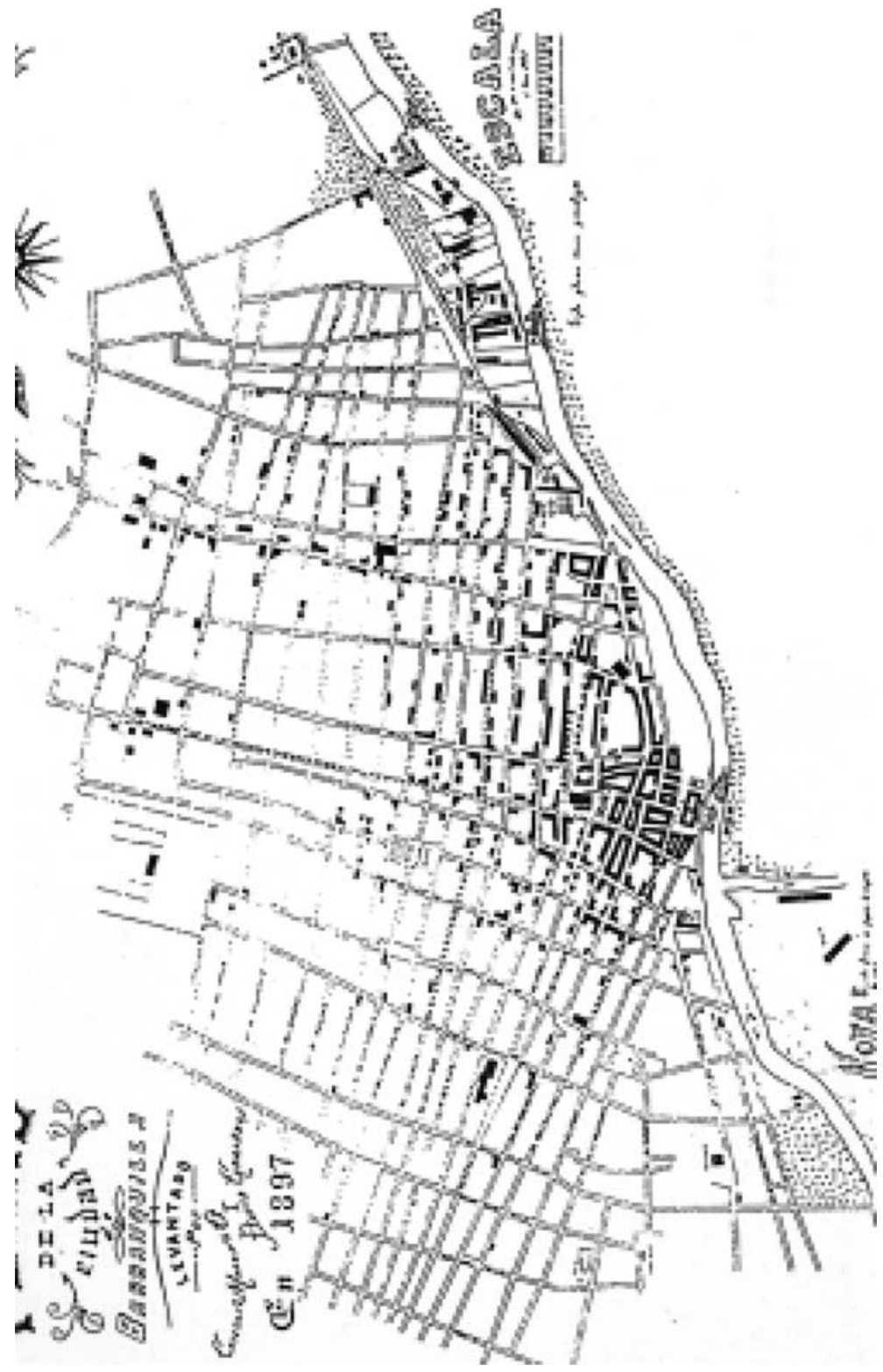

Fuente: Archivo General de la Nación. Tomado en: (Ospino Contreras, 2003) 
Plano 4. Plano de Barranquilla, año 1905. Autor desconocido

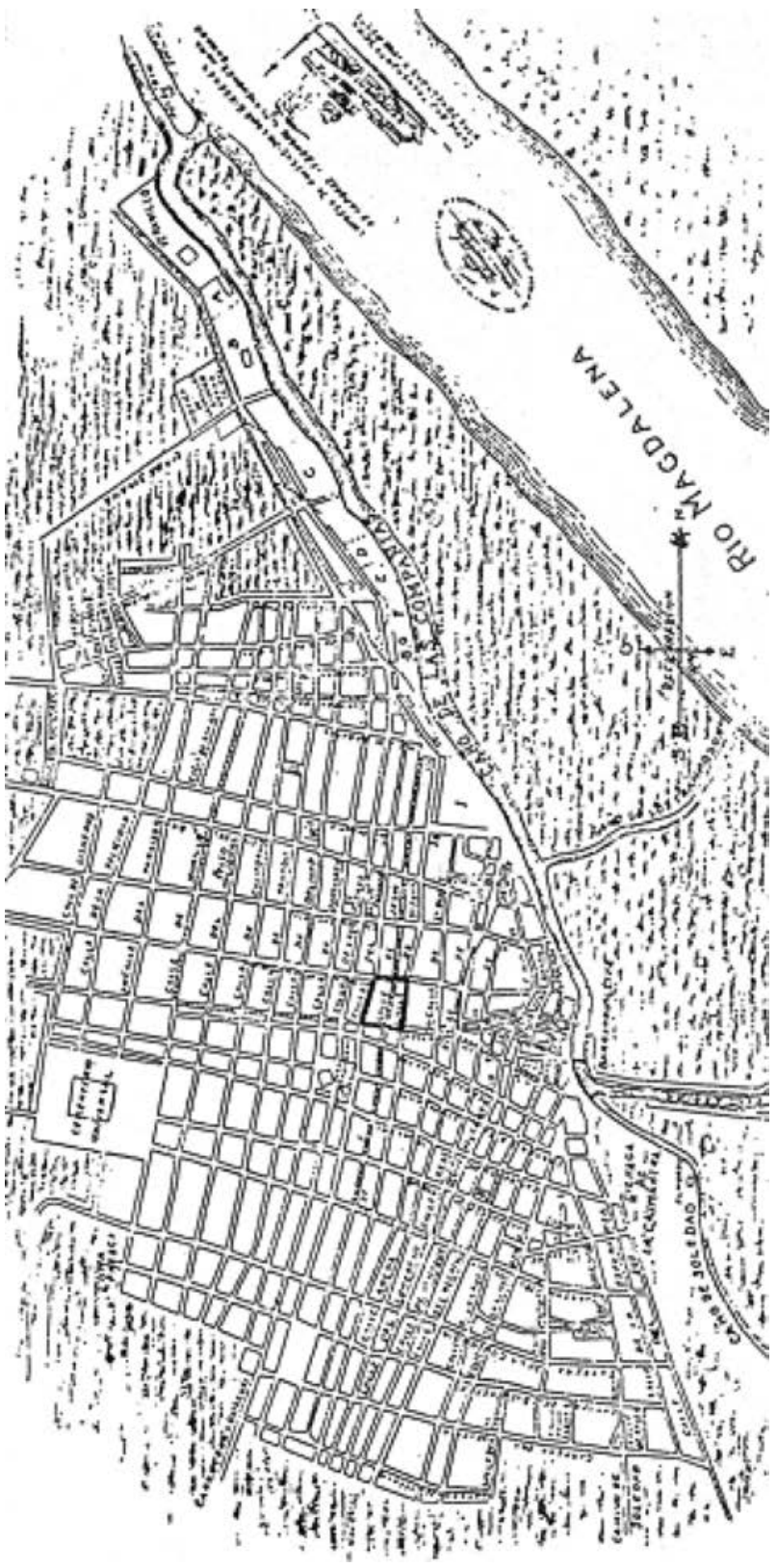

Fuente: Archivo del Departamento Administrativo de Planeación Departamental del Atlántico. Tomado en: (Ospino Contreras, 2003) 
Plano 5. Plano de Barranquilla, año 1922

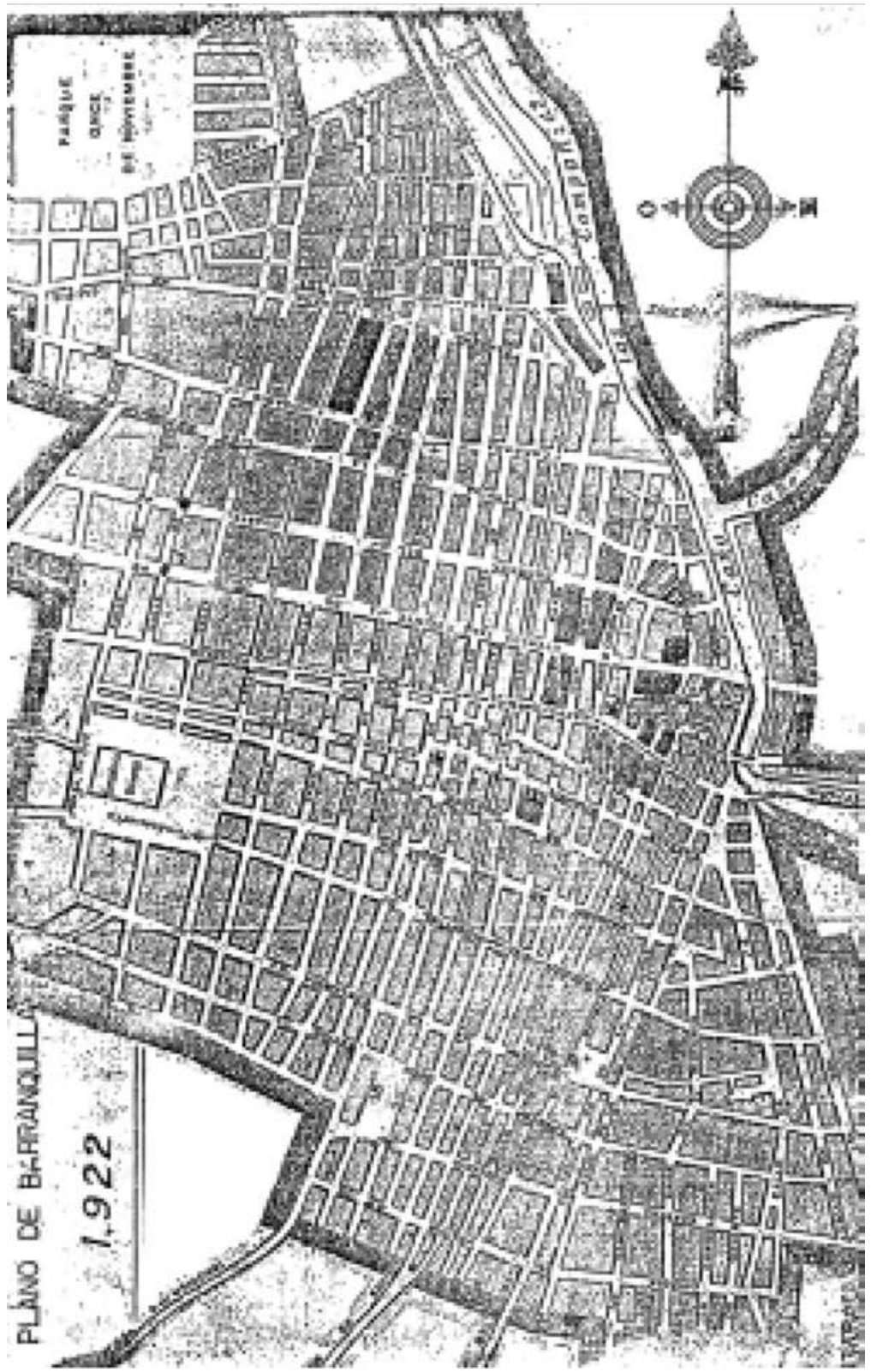

Fuente: Archivo del Departamento Administrativo de Planeación Distrital de Barranquilla.

Tomado en: (Ospino Contreras, 2003) 
Plano 6. Plano de Barranquilla, año 1922

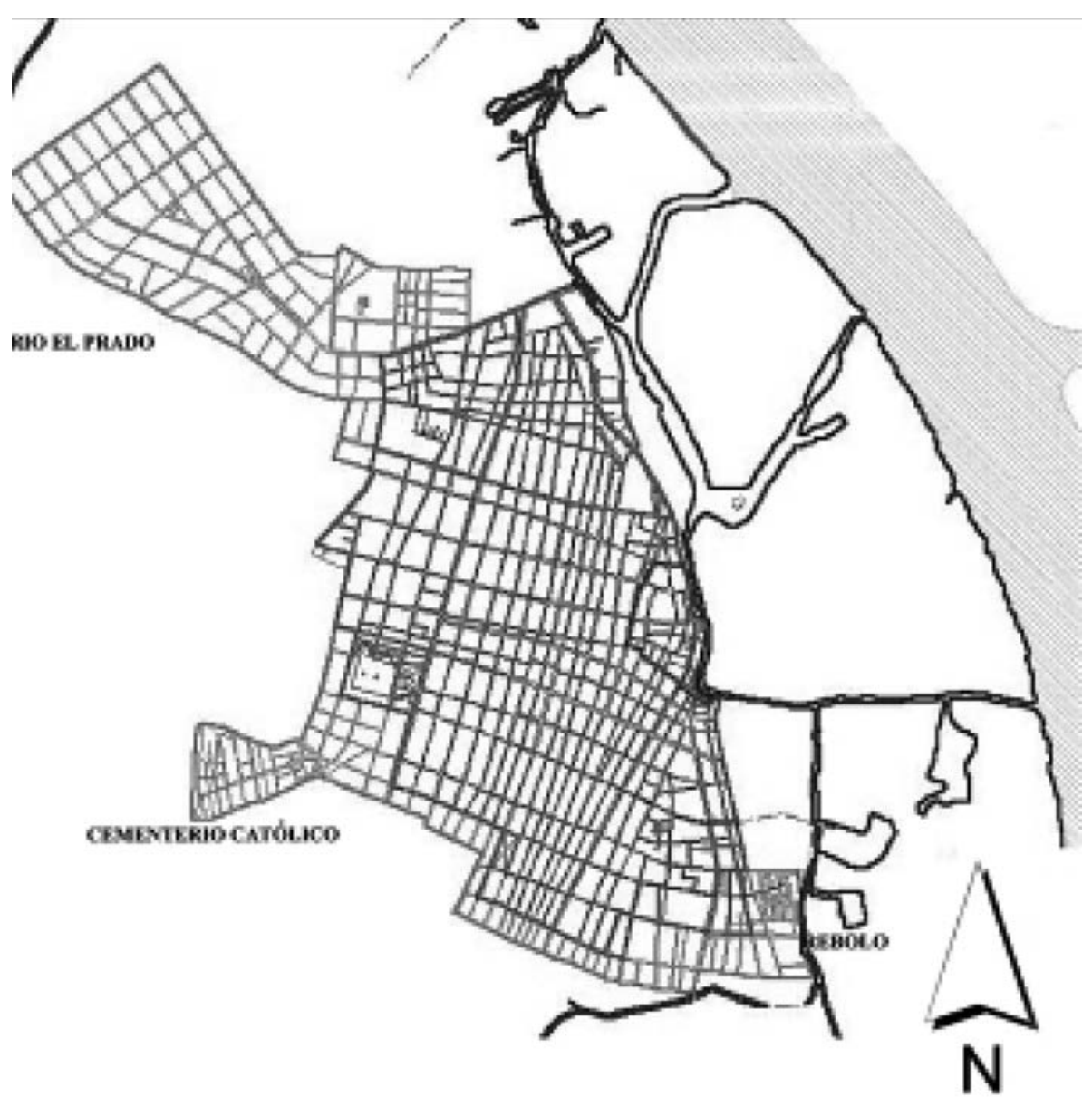

Fuente: aproximación realizada, con base en el plano anterior de 1922, por el autor en:

(Ospino Contreras, 2003) 
Plano 7. Plano de Barranquilla, año 1944

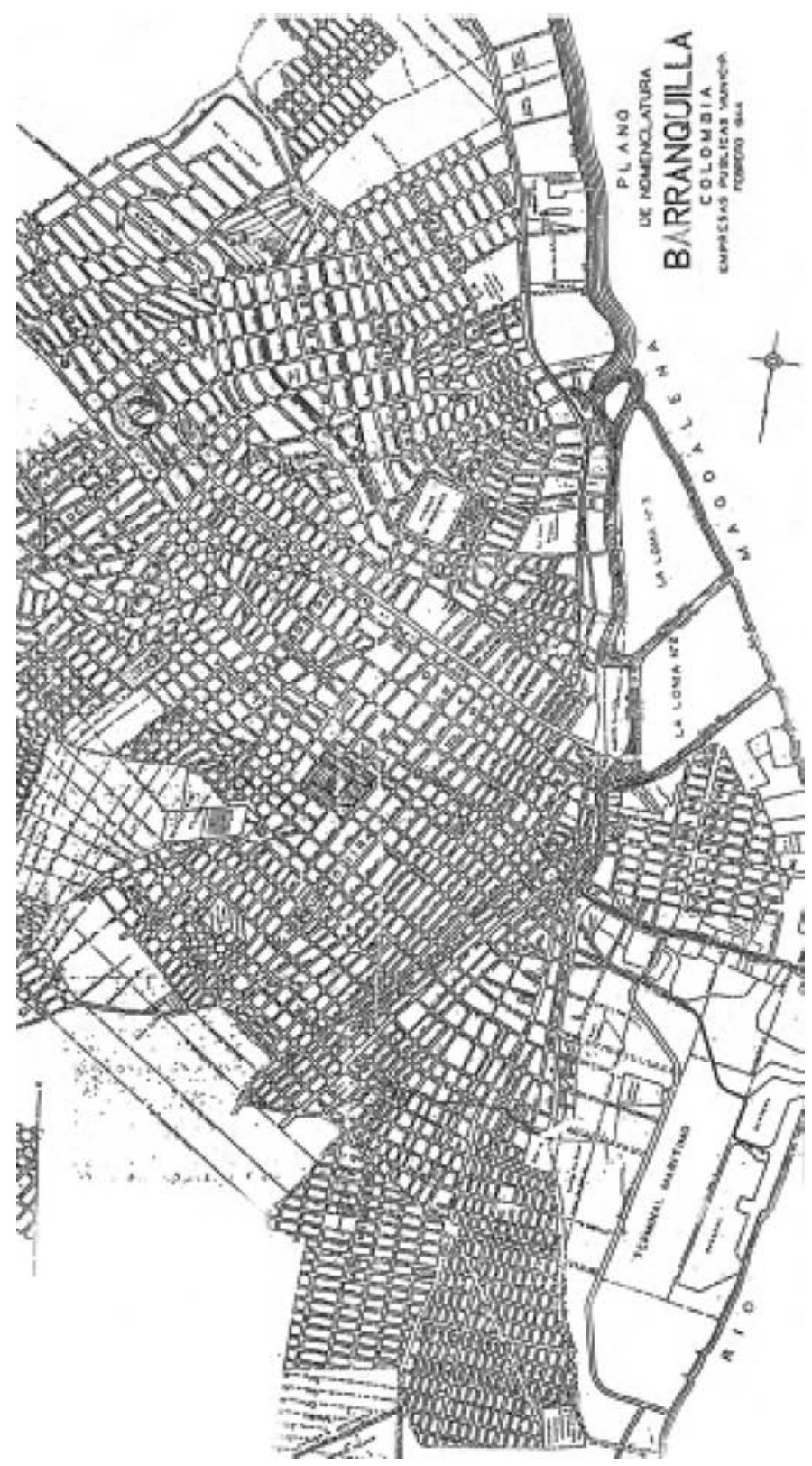

Fuente: Empresas Públicas municipales de Barranquilla. Tomado en: (Ospino Contreras, 2003) 
Plano 8. Extracto de las curvas de nivel y los arroyos de Barranquilla, año 1950. Elaborado por las Empresas Públicas municipales de Barranquilla

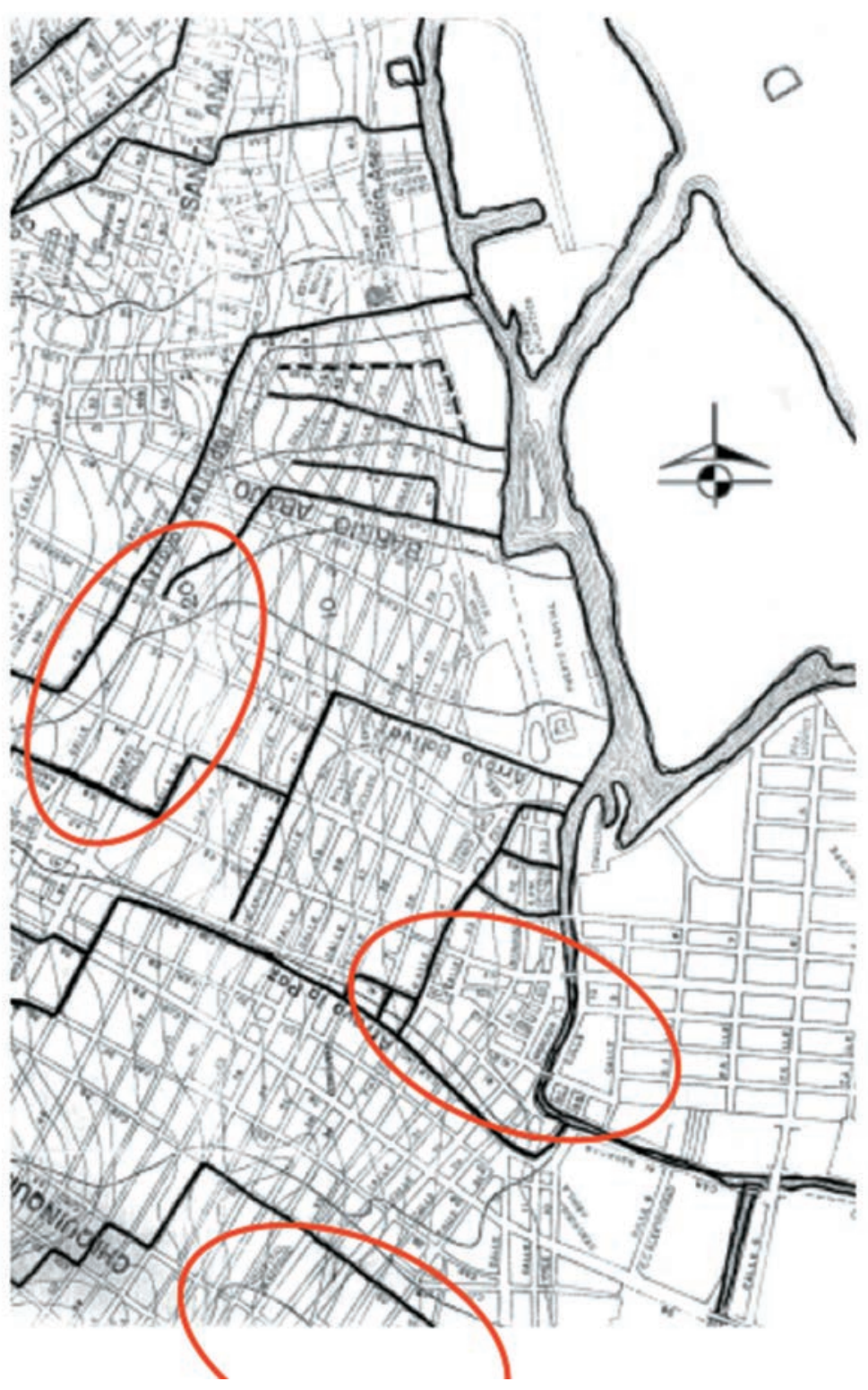

Fuente: Archivo del Departamento Administrativo de Planeación Distrital de Barranquilla. Tomado en: (Ospino Contreras, 2003) 
Plano 9. Plano de Barranquilla, año 1957

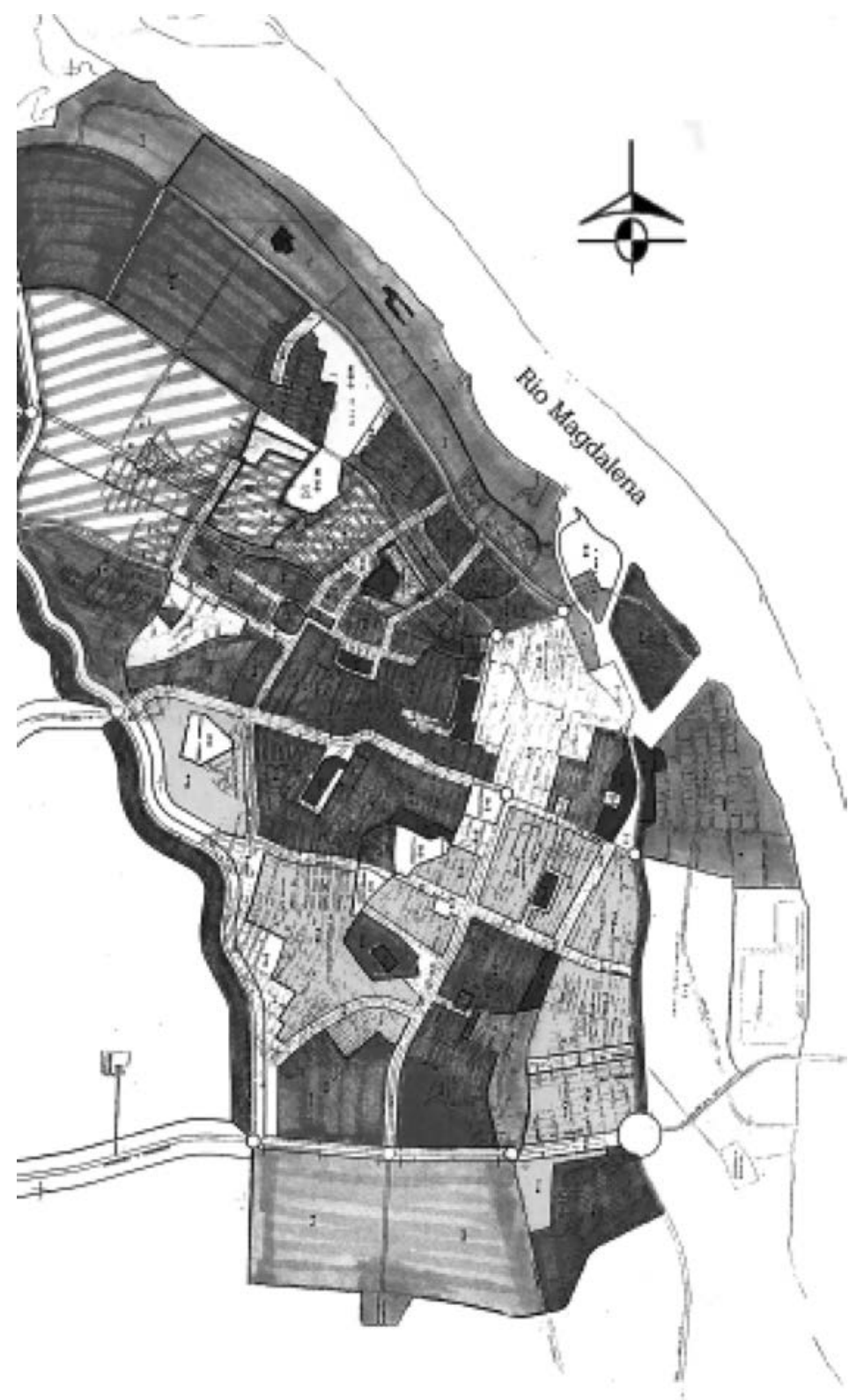

Fuente: Documento del Plan Regulador de 1957, Archivo del Departamento Administrativo de Planeación Distrital de Barranquilla. Tomado en: (Ospino Contreras, 2003) 
Plano 10. Plano de Barranquilla, año 1965

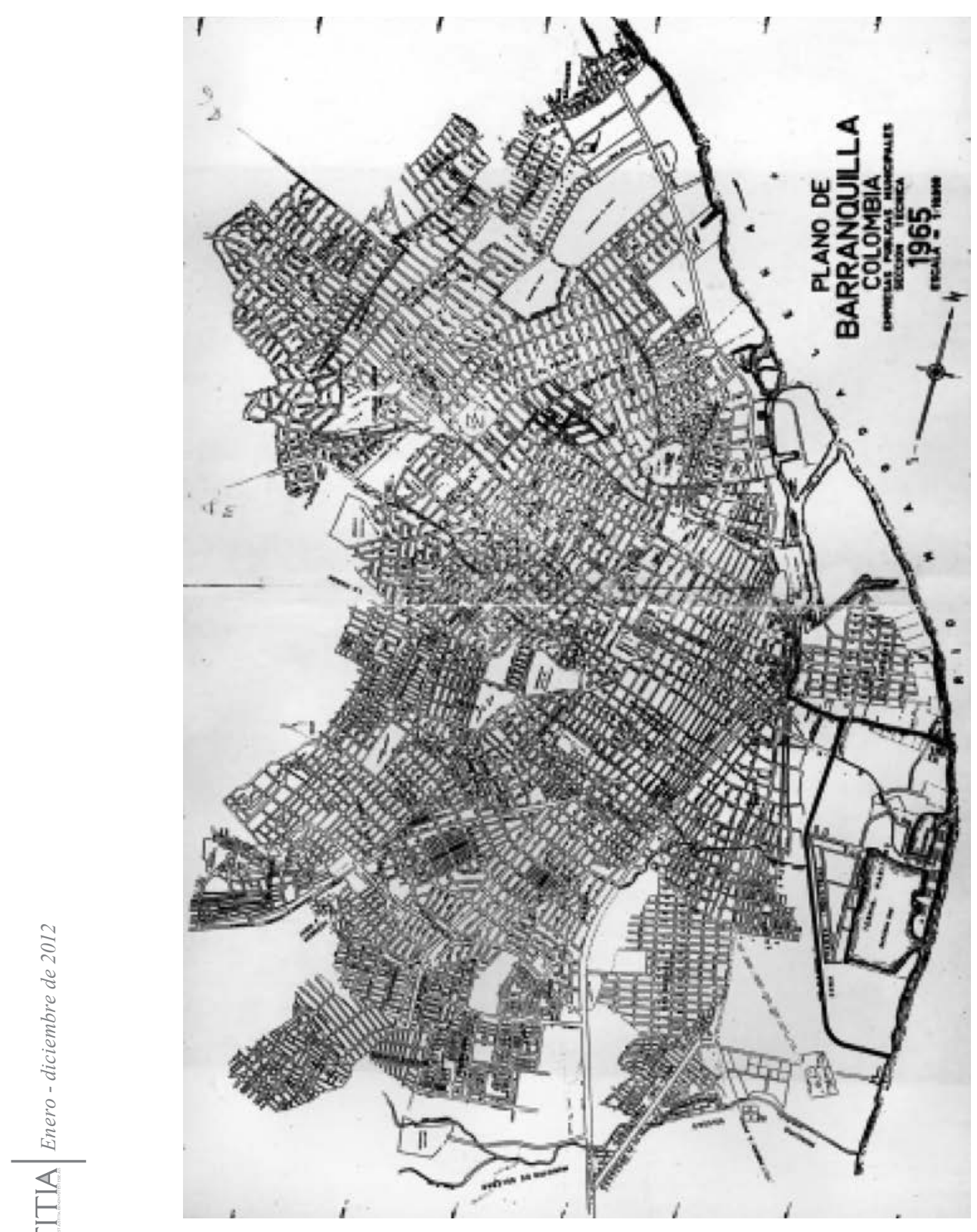

Fuente: Empresas Públicas Municipales de Barranquilla. Tomado en: (Ospino Contreras, 2003) 
Plano 11. Plano de Barranquilla, año 1983



Fuente: Misión de la Agencia de Cooperación Internacional Japonesa (JICA por sus siglas en inglés). Tomado en: (Ospino Contreras, 2003) 
Plano 12. Plano de Barranquilla, año 1993

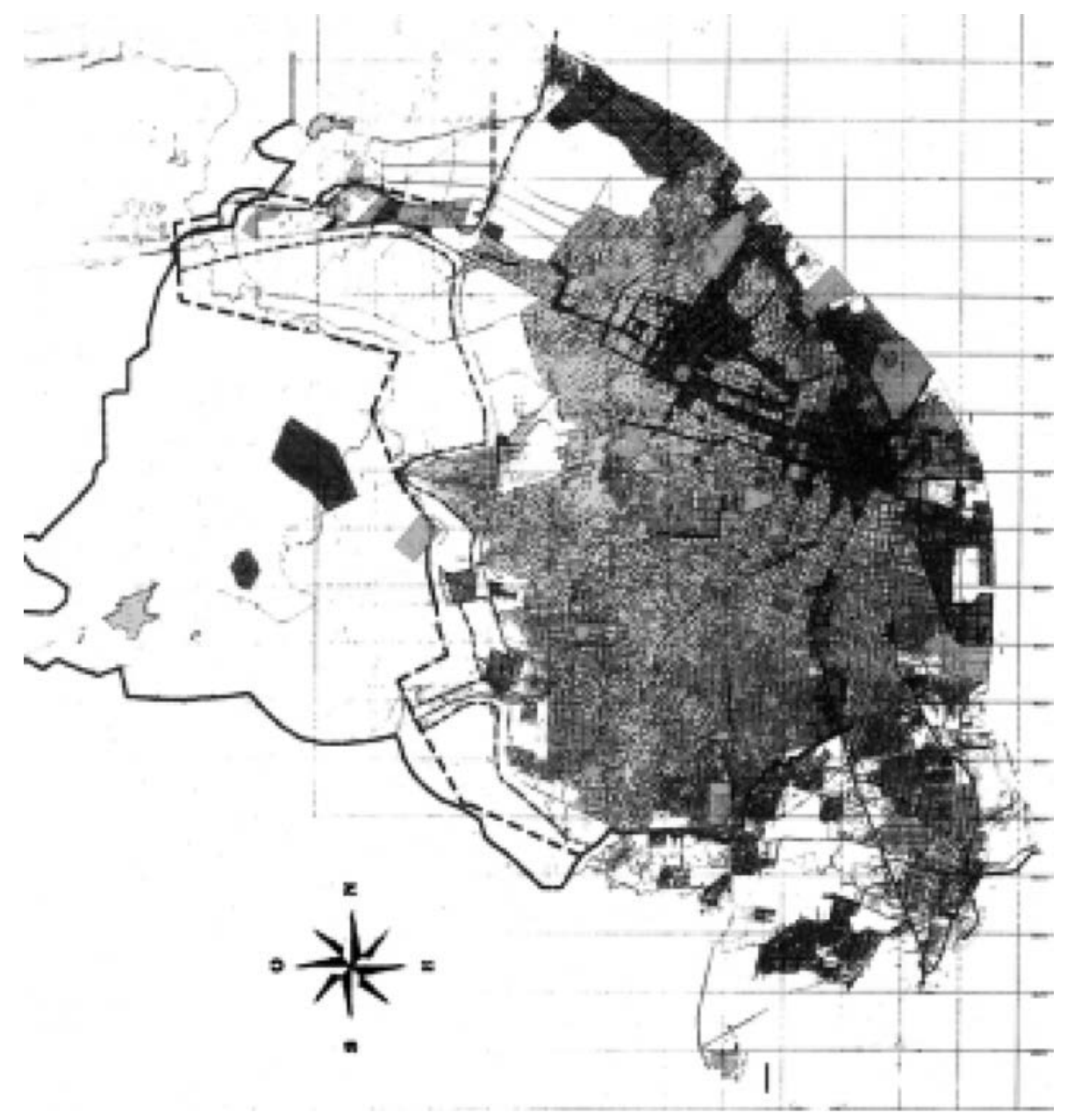

Fuente: Departamento Administrativo de Planeación Distrital de Barranquilla.. Tomado en: (Ospino Contreras, 2003) 
Plano 13. Plano del crecimiento histórico de Barranquilla, desde 1777 hasta 1993

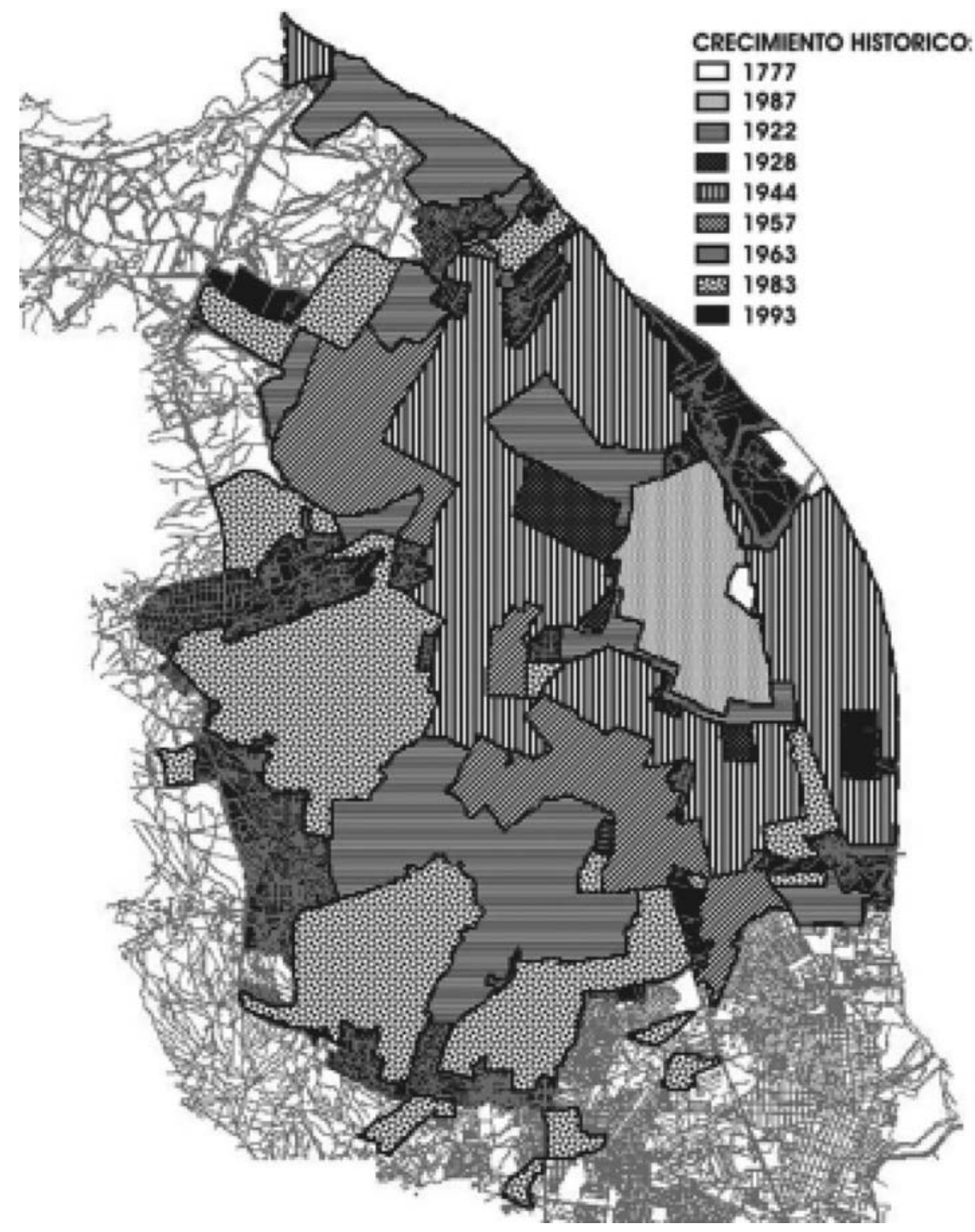

Fuente: Diseñado por Ospino Contreras con base en la cartografía del Departamento Nacional de Estadística DANE. Tomado en: (Ospino Contreras, 2003) 


\section{REFERENCIAS}

Aguilar, A. (diciembre de 2002). Las Megaciudades y las periferias extendidas. Ampliando el concepto en Ciudad de Mexico. Recuperado el 12 de julio de 2011, de Scielo, articulos de investigación: http://www.scielo.cl/scielo.php?pid= S0250-71612002008500007\&script $=$ sci_arttext

Ancízar, M. (1853). Peregrinación de Alpha: por las provincias del norte de la Nueva Granada en 1850 i 51. Bogotá: Editorial Echevarría.

Área Metropolitana de Barranquilla. (2004). Diagnóstico del Área Metropolitana de Barranquilla . Barranquilla: AM.

Baena, F., \& Vergara, R. (1922). Barranquilla, su pasado y su presente. Barranquilla: Banco Dungand.

Castells, M. (1976). La Cuestión Urbana. Madrid: Siglo XXI de España Editores, S.A.

D’Epagnanat, P. (1971). Recuerdos de la Nueva Granada.Bogotá: Biblioteca Schering de Colombia.

Descartes, R. (1986). El Discurso del Método. Barcelona: Planeta P.6.

Ferez Santander, E. M., \& Feres, M. P. (2008). Los usos y los propietarios del suelo en Barranquilla en la Década de los 30. Barranquilla: MEMORIAS Revista Digital de Historia y Arqueología desde el Caribe colombiano.

Fray SIMÓN, p. (1882). Noticias Historiales de las Conquistas de Tierra Firme en las Indias Occidentales. Pirmera parte. Bogotá: Imprenta de Medardo Rivas.

García Pacheco, L. E. (2007). Plan Especial de Protección de los barrios Prado, Alto Prado y Bella Vista. Barranquilla: UniNorte.

Instituto de Crédito Territorial. (1976). Inventario de zonas subnormales de vivienda y proyectos de desarrollo progresivo. Bogotá: ICT.

Llanos Enríquez, E. (2007). Proceso de transformación espacial de Barranquilla en el Siglo XX. Perspectiva Geográfica. No. 12, 9-35.

Meisel Roca, A. (1994). Rezago relativo y creciente integración 1950-1994. Barranquilla: Ediciones Uninorte.

Meisel Roca, A., \& Posada Carbó, E. (1993). Por qué se disipó el dinamismo industrial de Barranquilla. Barranquilla: Ediciones Gobernación del Atlántico.

Méndez, R. (1997). Geográfica Económica. La lógica espacial del capitalismo global. Madrid: Ariel.

Mertins, G. (2004). Transformaciones recientes en las metrópolis latinoamericanas y repercusiones espaciales. Perspectiva geográfica 10, 109-126.

Mertins, G. (2007). Estudios Urbanos - regionales desde el Caribe: el crecimiento "moderno" espacial - urbano en Barranquilla: ¡Planeación pública - oficial o manejo del sector privado? Revista Digital de Historia y Arqueología desde el Caribe REDALYC, 6-7. 
Ospino Contreras, P. (2003). El desarrollo urbano de Barranquilla y su dinámica regional 1777-1993. En L. E. Sánchez Bonett, Barranquilla: lecturas urbanas (p. 3-43). Bogotá: Observatorio del Caribe - Universidad del Atlántico.

Saldarriaga Roa, A. (1996). Estado, Ciudad, Vivienda Urbana y Arquitectura estatal en Colombia. 1918-1990. Santafé de Bogotá D.C.: Puntos suspensivos editores.

Sánchez Bonett, L. E. (2003). Barranquilla: Lecturas Urbanas. Bogotá: Observatorio del Caribe Colombiano - Universidad del Atlántico.

Sassen, S. (1991). The Global City. New York, London, Tokyo. New Jersey: Princeton University Press.

Solano, S. P. (1989). Comercio, transporte y sociedad en Barranquilla durante la primera mitad del siglo XIX. Boletín cultural y bibliográfico del Banco de la República, Biblioteca Luis Ángel Arango , 24-34.

Solano, S. P. (1989). Ensayos fabriles y estructura ocupacional en Barranquilla a finales del siglo XIX. Revista informativa de la Cámara de Comercio de Barranquilla, 8-11.

Solano, S. P. (2008). Barranquilla a finales del siglo XVIII y comienzos del XIX. Revista de Estudios Sociales, Universidad de los Andes, 34-47.

Villalón Donoso, J. (2005). Barranquilla en la historia. Foro: Barranquilla, memoria arqueológica, histórica y ambiental e el macro de los encuentros ambientales 2005. Recuperado el 17 de 6 de 2011, de www.uninorte.edu.co: http://www. uninorte.edu.co/extensiones/IDS/Ponencias/BARRANQUILLA\%20EN\%20 LA\%20HISTORIA $\% 20$ (conferencia\%20de\%20Jorge $\% 20$ Villalon).pdf 